\title{
What are the levels and mechanisms/processes of language evolution?
}

\author{
Nathalie Gontier \\ Applied Evolutionary Epistemology Lab, Center for Philosophy of Science, University of Lisbon, Portugal
}

\section{A R T I C L E I N F O}

Article history:

Available online 22 July 2017

\section{Keywords:}

Evolutionary Linguistics

Origin and evolution of language

Units and levels of evolution

Evolutionary mechanisms

Processes

Hierarchies

Extended Synthesis

Applied Evolutionary Epistemology

Philosophy of biology

\begin{abstract}
A B $S$ S $T$ R A A C
Modern evolutionary biology is currently characterized by epistemological divergence because, beyond organisms and genes, scholars nowadays investigate a plurality of units of evolution, they recognize multilevel selection, and especially from within the Extended Synthesis, scholars have identified a plurality of evolutionary mechanisms that besides natural selection can explain how the evolution of anatomical form and functional behavior occur. Evolutionary linguists have also implicated a multitude of units, levels and mechanisms involved in (aspects of) language evolution, which has also brought forth epistemological divergence on how language possibly evolved. Here, we examine how a general evolutionary methodology can become abstracted from how biologists study evolution, and how this methodology can become implemented into the field of Evolutionary Linguistics. Applied Evolutionary Epistemology (AEE) involves a systematic search and analysis of the units (that what evolves), levels (loci where evolution takes place), and mechanisms (means whereby evolution occurs) of language evolution, allocating them into ontological hierarchies, and distinguishing them from other kinds of evolution. In this paper in particular, we give an in-depth analysis of how AEE enables an identification, examination, and evaluation of levels and mechanisms of language evolution, and we hone in on how hierarchies and mechanisms of language (evolution) can and have been defined differentially. For an in-depth analysis of units of language evolution, we refer the reader to Gontier (2017) for which this paper functions as a follow-up. Thus, rather than present a specific theory of how language evolved, we present a methodology that enables us to unite existing research programs as well as to develop theories on the subject at hand.
\end{abstract}

(c) 2017 Elsevier Ltd. All rights reserved.

\section{Introduction}

The evolution of language is studied from within different disciplines, and all have identified a multitude of what can be called units (elements that evolve), levels (loci where these elements evolve), and mechanisms (conditions or processes according to which these elements evolve at certain loci) of language evolution. This multitude necessitates a pluralistic stance on both the nature of language and how language evolves. And here, Evolutionary Linguistics can learn from evolutionary biology and evolutionary epistemology, where scholars nowadays also investigate a plurality of units of evolution, they recognize multilevel selection, and especially from within the Extended Synthesis, scholars are identifying a plurality of evolutionary mechanisms that besides natural selection can explain how evolution occurs.

Abbreviations: LE, language evolution; EE, evolutionary epistemology; AEE, Applied Evolutionary Epistemology.

E-mail address: nlgontier@fc.ul.pt.

URL: http://appeel.fc.ul.pt 
In this paper, under (2), we analyze how scholars active in traditional evolutionary epistemology and Universal Darwinian have reformulated natural selection theory in order for the latter to not only account for the evolution of biological form but also for the evolution of cognition, behavior, language and sociocultural phenomena. This research has led to the identification of new units and levels of evolution. The recognition of unit and level pluralism, in turn, has resulted in a questioning of the boundaries that a previous generation of researchers assumed there existed between the inorganic (physical and chemical), organic (biological), and superorganic (sociocultural). And this requires us to build new hierarchical views of how the biological and sociocultural relate to one another.

In part (3), we hone in on how the Extended Synthesis has made us recognize that evolution can occur by a multiplicity of mechanisms and processes. This recognition of mechanism pluralism adds to the complexity of how we study language evolution, because on the one hand, we often cannot straightforwardly link a specific biological evolutionary mechanism to the trait of which we want to study how it evolved, and on the other, there also exist mechanisms specific to cognitive, social, cultural and linguistic evolution (Zywiczynski et al., 2017). Applied Evolutionary Epistemology (AEE) is a methodology that enables us to cope with this unit, level and mechanism pluralism, and we detail how the methodology can become implemented into Evolutionary Linguistics.

In part (4), we examine how existing research programs in (evolutionary) linguistics have already tackled the problem of identifying the units, levels and mechanisms of language (evolution), and how they have conceptualized the ontological hierarchies relevant for language (evolution). We provide a tentative ordering of the existing data, and demonstrate how AEE enables unification of the ongoing research endeavors.

Under (5), we demonstrate how AEE not only enables an ordering of existing data. It also provides a research methodology in the form of three heuristics that enable an identification, examination and evaluation of units, levels and mechanisms of language evolution, how they can be allocated into ontological hierarchies, and how language evolution can be differentiated from other kinds of evolution.

Finally, in parts (6) and (7), we give an in-depth analysis on how we can in particular identify and analyze the various levels or loci where language evolves, and, the various mechanisms and processes whereby language evolves. For an in-depth analysis of the unit-heuristic, we refer the reader to Gontier (2017), for which this paper functions as a follow-up.

Thus rather than present a theory of language evolution, in this paper we present a methodology that enables us to unify existing research programs as well as to develop theories on when and how language evolved.

\section{Traditional evolutionary epistemology (EE) and Universal Darwinism}

Natural selection theory is a theory that first developed in the biological sciences with the primary objective to explain the evolution of biological species, in particular their shared anatomical form, common descent, and diversity (speciation and extinction). Traditional EE (Bradie, 1986; Campbell, 1960, 1974a) initiated from early attempts to apply natural selection theory to phenomena originally studied outside the field of biology, including cognition (originally studied from within psychology), behavior (ethology), language (linguistics) and sociocultural phenomena (sociology and anthropology). In order to apply natural selection theory to cognitive, behavioral, linguistic and sociocultural phenomena, scholars have "universalized" natural selection theory by examining how it can operate on units other than genes or organisms. That is why this approach has also been called Universal Darwinism (Dawkins, 1983) and Universal Selectionism (Cziko, 1995).

How then did these scholars "universalize" natural selection?

For one, scholars have investigated under what conditions the mechanism of natural selection operates, and these conditions have either been formulated in terms of heuristics such as "blind variation and selective retention" (Campbell, 1960, 1974a) or logical skeletons of natural selection, that focus on the three Darwinian principles of "differential variation, inheritance and differential fitness" (Lewontin, 1970).

Secondly, such research has brought forth the units (Lewontin, 1970) and levels (Brandon, 1982) of selection debate. Beyond genes and organisms, which have long been considered the only units of natural selection, scholars have introduced concepts such as replicators and memes (Dawkins, 1982), interactors (Hull, 1981), culturgens (Boyd and Richerson, 1985), linguemes (Croft, 2000), and reproducers (Griesemer, 2000) to investigate what kind of entities can evolve by means of natural selection.

Thirdly, scholars have recognized that such units can become selected at multiple levels of an evolutionary hierarchy (Hull, 1981; Okasha, 2005, 2006). A gene, for example, can be the target of selection at the level of the organism, group, or species, and the latter three are entities that together form a genealogical hierarchy that is based upon common descent (Eldredge and Salthe, 1984; Tëmkin and Eldredge, 2015). And a lingueme (Croft, 2000), for example, underlies an individual's idiolect, but the lingueme is also altered by dialects and sociolects in cultural ecology (Mufwene, 2001).

In sum, classic EE brought forth research on the units of selection, the levels where selection occurs, and how these units and levels combine into the classic evolutionary hierarchy of genes, organisms and species (Hull, 1980, 1981).

\section{The Applied Evolutionary Epistemological approach (AEE)}

Applied Evolutionary Epistemology (Gontier, 2010a, 2010b, 2012, 2013, 2017) is a scientific and philosophical methodology used to conduct evolutionary research. It builds on the research methodologies associated with classic evolutionary 
epistemology and Universal Darwinism, and it applies this methodology to evolutionary theories currently associated with an Extended Synthesis.

In this part, we first briefly describe the Extended Synthesis (Section 3.1), and subsequently, we present a new definition of evolution that enables us to define units, levels and mechanisms in a selection-neutral way (Section 3.2). This definition also informs us on how we can study evolution. Afterwards, we hone in on how relations between units and levels have been conceptualized from within hierarchy theories, and how hierarchy theories in turn function as a means to conceptualize causality and mechanisms (Section 3.3). We end this part by listing some of the consequences of AEE (Section 3.4).

\subsection{The Extended Synthesis}

Scholars active in the biological and sociocultural sciences have come to realize that, besides by means of natural selection, evolution can occur by a multitude of mechanisms and processes, including epigenetic and evo-devo mechanisms (that bring forth phenomena such as developmental plasticity, phenotypic accommodation, and niche construction), reticulate mechanisms (hybridization, symbiogenesis and mechanisms that enable lateral gene transfer), and molecular and ecological drift (Arnold, 1997; Hallgrîmsson and Hall, 2011; Hubbell, 2001; Jablonka and Lamb, 1989; Keeling and Palmer, 2008; Kimura, 1983; Lewontin, 1983; Margulis, 1998; Odling-Smee, 1988; West-Eberhard, 2005).

The investigative range of these research fields surpass the scope of the classic Modern Synthesis that merely combined Darwinian selection theory with Mendelian hereditary laws and genetic mutation theory to explain the evolution and diversification of anatomical form. Scholars have therefore argued that the Modern Synthesis is incomplete (Gould and Eldredge, 1977; Margulis, 1998; Gontier, 2015a,b; Serrelli and Gontier, 2015), and to overcome classic disciplinary divisions, scholars have either called out for an Extended Synthesis that integrates development and ecology (Pigliucci, 2009), or they have called out for a whole new biology that in addition recognizes the important role played by reticulate evolutionary mechanisms (Woese, 1998). These debates have brought forth discussions on the mode and tempo of evolution, and it has divided biological disciplines into micro-, meso- and macro-oriented research approaches, where scholars respectively study evolution from within molecular genetics, development, and ecology.

It has also divided the sociocultural evolutionary sciences, where some scholars have argued that social organization and cultural phenomena can be reduced to biological processes (Cosmides and Tooby, 2007; Maynard Smith, 1982; Wilson, 1975), while others have pointed out that there exist mechanisms particular to sociocultural evolution (Boyd and Richerson, 1985; Cavalli-Sforza and Feldman, 1981; Deacon, 1997; Lumsden and Wilson, 1981). These ongoing debates by no means facilitate the job of evolutionary linguists, because when taking these advances into account, it often becomes difficult to straightforwardly link the traits we study to the mechanisms whereby they evolved (be they biological or sociocultural in kind), and in so far as language evolution is a phenomenon unique to our species, it is likely that here too, additional units, levels and mechanisms can be identified.

\subsection{AEE's definition of evolution}

Applied Evolutionary Epistemology (AEE) is a methodology that enables us to cope with this unit, level and mechanism pluralism. Though research schools are divided, scholars that are currently investigating how the Modern Synthesis can become extended continue to investigate how the non-selectionist mechanisms they have identified enable the evolution of units, and they continue to examine at which levels in an ontological hierarchy such evolution occurs (Gontier, 2010a; Gontier and Bradie, forthcoming). And this in turn informs us on the nature of evolution itself, because any and all evolutionary phenomena (e.g. the evolution of anatomical form, cognition, behavior, language or culture) seem to occur when units evolve at levels of an ontological hierarchy by mechanisms. This characterization of evolution can function as a universal definition that enables us to find common ground (Table 1). And from this definition, we can abstract a universal methodology to study evolution, namely, the study of any kind of evolution involves an identification of units, levels, and mechanisms, and allocating them into an ontological hierarchy.

Table 1

Applied Evolutionary Epistemology.

1. Universal definition of evolution

Evolution occurs when unit/s evolve (change) at level/s of an ontological hierarchy by mechanism/s

2. A derived universal evolutionary methodology

Studying evolution involves a search for units, levels, and mechanisms, and allocating them into an ontological hierarchy

There is much to be gained by recognizing that evolution is no longer synonymous to "that what evolves by means of natural selection", and we can also surpass ongoing debates on which mechanisms are more important than others, or what the true, intrinsic nature of units and levels is. Instead of defining units, levels and mechanisms based upon selection theory, AEE provides neutral definitions for units (what), levels (where) and mechanisms whereby (how) phenomena evolve (Table 2). 
Table 2

Ostensive and extensional/denotative definitions of units, levels and mechanisms.

\begin{tabular}{|c|c|c|c|}
\hline & $\begin{array}{l}\text { Epistemic } \\
\text { question }\end{array}$ & $\begin{array}{l}\text { Extensional/denotative } \\
\text { definition }\end{array}$ & Ostensive definition (definition by pointing) \\
\hline Unit & What & The entity that evolves & $\begin{array}{l}\mathrm{X} \text { is a unit if one can minimally point out one level } \\
\text { where } \mathrm{x} \text { evolves, and one mechanism whereby } \mathrm{x} \text { evolves }\end{array}$ \\
\hline Level & Where & $\begin{array}{l}\text { The locus where evolution occurs } \\
\text { in an ontological hierarchy }\end{array}$ & $\begin{array}{l}\mathrm{X} \text { is a level if one can minimally point out one unit } \\
\text { that evolves by minimally one mechanism at } \mathrm{X}\end{array}$ \\
\hline Mechanism/process & How & $\begin{array}{l}\text { The means/conditions whereby } \\
\text { evolution occurs }\end{array}$ & $\begin{array}{l}\mathrm{X} \text { is a mechanism if one can minimally point out one } \\
\text { unit that evolves at one level by means of } \mathrm{X}\end{array}$ \\
\hline
\end{tabular}

AEE proposes to avoid intensional definitions, and instead it proposes that units, levels and mechanisms are defined extensionally (denotative), and that they are identified ostensively (by demonstration). Extensionally, units refer to the entity that evolves, levels to the locus where evolution occurs in an ontological hierarchy, and mechanisms refer to the means or conditions whereby evolution occurs. And given that empirical evidence suggests that evolution always occurs when units evolve at levels by means of mechanisms, AEE also adds an ostensive (demonstrative) requirement to the identification of either three. Units can be identified by pointing out the level where, and the mechanism whereby it evolves; levels can be identified by pointing out the units that evolve at that level by mechanisms; and mechanisms can be identified by pointing out the units that evolve by that mechanism at levels. Note that the intensional definitions are not circular. The act of identification of one element requires the identification of the other two, which is different for each separate identification act (for a more elaborate discussion, see Gontier, forthcoming).

\subsection{Defining mechanisms from within ontological hierarchies}

AEE favors a pragmatic approach to how we define units, levels and mechanisms. Nonetheless, there does exist a more metaphysical part to both the theory and the methodology when we analyze how units and levels form ontological hierarchies. And hierarchies, in turn, are the means par excellence whereby scientists have defined and investigated the means and conditions, i.e. the mechanisms, whereby evolution occurs. In this part, we first analyze how scholars have conceptualized hierarchies (Section 3.3.1), and then we investigate how these hierarchies have been foundational for how we conceptualize causality and mechanisms (Section 3.3.2).

\subsubsection{Units, levels and hierarchies}

Units and levels can be understood respectively as the parts and wholes that make up hierarchies, and hierarchy theory is the classic means whereby we try and make sense, epistemologically, of the ontological layeredness or complexity of the world (Simon, 1962). How we understand and depict hierarchical complexity has itself been a cultural and scientific learning process, and we can even distinguish the different Western cosmologies from one another by examining how they theorize and depict complexity (Gontier, 2016b).

Over the years, scholars have classified our epistemic knowledge of the world into:

1. Aggregational hierarchies (Mayr, 1982) or artificial classification systems, examples include Linnaean or traditional language classifications that were based upon affinities or logical principles such as binary oppositions;

2. Linear hierarchies that outline the trajectories of units in time or space, and these trajectories are often depicted as timelines or chains (Gontier, 2011), examples include classic historicist timelines as they were introduced in early natural history research that included historical linguistics (further discussed under Section 4.2.1);

3. Constitutive (Mayr, 1982), embedded (Pattee, 1973) or nested hierarchies (Grene, 1987) that conceptualize how a structural or functional arrangement of parts/units organizes into a new level/whole that demonstrates emergent properties, and visualizations of these hierarchies often take on the form of bifurcating tree diagrams or cycles (Bechtel, 2011), an example is the classic evolutionary hierarchy (Hull, 1981), where genes constitute organisms that constitute species; and

4. Interactional hierarchies that help to conceptualize how units and levels interact within and between different hierarchies, which in scientific practice often relates to the development of network diagrams (Gontier, 2016b), examples include the network diagrams used to depict macroevolutionary change as it occurs through interactions between the units and levels that constitute the genealogical and ecological hierarchy (Tëmkin \& Eldredge, 2015), or the networks that today depict sociocultural and linguistic change in both time and space (history and ecology).

All sciences, including the biological, anthropological and linguistic ones, have gone through phases of depicting their research area in artificial classification systems, followed by timelines, trees, and networks, and the above listed hierarchies therefore themselves represent a chronology of how scholars have learned to conceptualize complexity (and see also Morrison, 2016).

\subsubsection{Hierarchies, causality and mechanisms}

These hierarchies furthermore lend insight into how scholars have sought to describe and explain ontology and how they have conceptualized causality. And in so far as mechanisms define the causes of evolution, the hierarchies also lend insight into how we have learned to conceptualize mechanisms (Table 3). 
Aggregational hierarchies mainly function to describe rather than to explain recurring states of phenomena, and therefore do not assume causality between the parts that are classified into an aggregational whole.

Linear hierarchies either describe the trajectory taken by the units that constitute the whole over time, or they focus on a spatial arrangement of the elements that constitute a hierarchy. Linear hierarchies therefore give a one-dimensional outline of events, either focusing on spatial or temporal aspects. One can describe the current spatial structure of a polymeric chain, for example, or one can describe its formation over time by detailing how molecule a was followed by molecule b, that was followed by molecule c, consecutively over time. The difference is best captured by the classic distinction between synchronic and diachronic linguistics that are both outgrowths of historical linguistics (de Saussure, 1916; Malinowski, 1922; Durkheim, 1922). Synchronically-oriented scholars describe the current state of linguistic or cultural systems, while diachronically-oriented scholars describe their trajectory, taken either in space or in time. Both research avenues continue to primarily focus on describing recurring patterns and pointing toward "factors" they hold responsible for a state of affairs, thereby avoiding evolutionary explanations. In diachronic linguistics, for example, Labov (2010) has pointed toward cultural and cognitive factors that help explain sociolinguistic change, but he does not understand language change as resulting from evolutionary mechanisms (we return to this under Section 4.2.1). Nonetheless, these factors and patterns can already be understood as causally explanatory, because they lend insights into what evolutionary biologists have come to call affordances and constraints imposed by the system (Gould, 1977; Futuyma, 2010). And these can be understood as mechanistic in so far as they enable or disable change.

But, returning to our polymer example, one can, and has wondered whether such a chronological line-up of the trajectory taken by the parts that constitute the whole, is sufficient to causally explain the origin of a polymer. For that, we also need to examine how the molecules bind to one another to form the chain, and that implies a biochemical explanation of the mechanisms whereby molecules bind. In the biological, linguistic and sociocultural sciences too, scholars have become unsatisfied with merely describing the current state and natural history of life, languages or cultures, and they have sought to explain how their spatial state and natural history came about, by finding the underlying evolutionary mechanisms.

This is traditionally done by developing nested hierarchies. Nested hierarchies order spatial arrangements in and over time, thereby providing a two-dimensional view of the world in, for example, a Cartesian coordinate system. Nested hierarchies help explain how units interact, thereby bringing forth a new, emergent whole. From within classic Cartesian mechanics, causality is often found by going down one level of a nested hierarchy, and examining how the structural and functional arrangements of the parts together bring forth new levels. And, as Simon (1962, pp. 478) already noted, the description of this path has often been substituted by a law that explains this path. But today, in the evolutionary sciences, we no longer think in terms of "laws" of nature. Instead, we often pursue with describing the paths, and what we today call "mechanisms" are therefore often process descriptions (Bechtel and Richardson, 1993; Machamer et al., 2000, pp. 3). In Campbell's heuristic of natural selection, "selective retention", for example, can refer to the process of gene replication during inheritance, or the process of learning cultural ideas. Both describe different paths taken by different units at different levels of a hierarchy, but both can be understood as selective.

Most hierarchies that are studied within the evolutionary sciences today are nested hierarchies, with a classic example being what Hull (1980) called the "evolutionary hierarchy" made up of genes, organisms, and species. Here, the higher levels contain the lower units of a nested hierarchy, and simultaneously, the levels form a new whole (which can be considered a new unit) with emergent properties not found in the individual parts. Nested hierarchies always have a dual element of control (Polyani, 1968; Grene, 1987, pp. 505), where lower units causally determine how new levels emerge, and the new levels, once in existence, often control the lower levels. Genes, for example, bring forth organisms, but once organisms exist, they control the distribution of genes through reproduction. Similarly, we have a biological constitution that enables us to learn language, but we learn the particular language we speak from the community we are born in. The former demonstrates a type of upward causality, and the latter demonstrates downward causality (Campbell, 1974b).

Table 3

Ways to conceptualize and visualize causal explanations by hierarchies.

\begin{tabular}{|c|c|c|c|}
\hline Type & Visualizations & Causality & Examples of explanations \\
\hline $\begin{array}{l}\text { Aggregational hierarchy: } \\
\text { Random collection of parts into an } \\
\text { unorganized whole }\end{array}$ & $\begin{array}{l}\text { Single set, circle or one- } \\
\text { level organizational } \\
\text { chart/organigram }\end{array}$ & $\begin{array}{l}\text { No causality, descriptive } \\
\text { explanation by pointing out } \\
\text { recurring patterns }\end{array}$ & $\begin{array}{l}\text { No causal mechanisms are assumed } \\
\text { Dutch is an official language in Belgium, the } \\
\text { Netherlands, Suriname, Aruba, Curaçao and } \\
\text { Sint Maarten. } \\
\text { The classificatory principle used for this } \\
\text { artificial hierarchy is "countries that have } \\
\text { Dutch as the official language" }\end{array}$ \\
\hline $\begin{array}{l}\text { Linear hierarchy: } \\
\text { Linear trajectory or sequence of parts }\end{array}$ & $\begin{array}{l}\text { Single line/trajectory, chain, } \\
\text { chronology }\end{array}$ & $\begin{array}{l}\text { Linear, consecutive } \\
\text { (continuous) } \\
\text { descriptive/causal } \\
\text { explanation }\end{array}$ & $\begin{array}{l}\text { Transition from descriptions to causal } \\
\text { explanations } \\
\text { Spatial explanation: Dutch was introduced } \\
\text { in Suriname by Dutch colonialists (the } \\
\text { linearity here lies in the control of the Dutch } \\
\text { in the spatial expansion of the language; } \\
\text { downward causality). } \\
\text { Consecutive explanation: Cape Dutch } \\
\text { dialects preceded Afrikaans (linearity as } \\
\text { continuity over time; forward causality) }\end{array}$ \\
\hline
\end{tabular}


Table 3 (continued)

\begin{tabular}{|c|c|c|c|}
\hline Type & Visualizations & Causality & Examples of explanations \\
\hline $\begin{array}{l}\text { Constitutive/Embedded/Nested hierarchy } \\
\text { (functional arrangement): } \\
\text { Structural or functional arrangement of } \\
\text { parts into a new level/whole; i.e. } \\
\text { horizontal, intra-level interactions } \\
\text { between parts bring forth a new whole, } \\
\text { that besides containing the parts, has } \\
\text { emergent properties }\end{array}$ & $\begin{array}{l}\text { Multi-level organizational } \\
\text { charts/organigrams, } \\
\text { bifurcating trees, Russian } \\
\text { dolls, circles, cycles (always } \\
\text { linearly consecutive, either } \\
\text { going up- or downward) }\end{array}$ & $\begin{array}{l}\text { Dual control } \\
\text { (Upward/reductionist } \\
\text { causality and } \\
\text { downward/holistic } \\
\text { causality)/cyclic causality } \\
\text { (regularly recurring up-and } \\
\text { downward causality) }\end{array}$ & $\begin{array}{l}\text { MECHANISMS } \\
\text { Upward causality: Afrikaans originates from } \\
\text { Cape Dutch dialects by (a series of) (non- } \\
\text { evolutionary) mechanisms; genes bring } \\
\text { forth organisms that bring forth groups that } \\
\text { bring forth species (explained by natural } \\
\text { selection occurring in a genealogical } \\
\text { hierarchy) } \\
\text { Downward causality: pastoralism facilitates } \\
\text { prolonged digestion of milk that induces } \\
\text { lactose-tolerance at an organismal and } \\
\text { genetic level (an example of the Baldwin } \\
\text { effect as it occurs within the ecological } \\
\text { hierarchy) } \\
\text { Dual control/Cyclic causality: an } \\
\text { ontogenetically acquired, genetic alteration } \\
\text { in lactose-tolerance, induced by pastoralism } \\
\text { (downward causality), can be passed on to } \\
\text { future generations (upward causality) } \\
\text { (explained by epigenetics) }\end{array}$ \\
\hline $\begin{array}{l}\text { Interactional hierarchy or hierarchies: } \\
\text { Nested hierarchies with horizontal, linear } \\
\text { (upward or downward), dual, cyclic, and } \\
\text { non-linear intra- and interlevel } \\
\text { interactions within that hierarchy and/or } \\
\text { between different hierarchies }\end{array}$ & Networks (non-linear) & $\begin{array}{l}\text { Non-linear and multiple } \\
\text { causalities }\end{array}$ & $\begin{array}{l}\text { MECHANISM PLURALITY } \\
\text { Non-linear causality: Microbes and humans } \\
\text { can and have induced climate change, and } \\
\text { climate change can and has induced } \\
\text { changes in the ecological, genealogical, and } \\
\text { developmental hierarchies }\end{array}$ \\
\hline
\end{tabular}

Especially in the biological sciences, this has brought forth polemic debates between micro-evolutionary, gene-reductionists (Dawkins, 1976; Mayr, 1961; Williams, 1966) and macro-evolutionary, holists (Eldredge, 1985). But in the sociocultural and linguistic sciences, downward causation is traditionally recognized to occur quite regularly, and reinforcing feedforward and feed backward loops between levels of a hierarchy, or concepts such as generative entrenchment or evolvability (Wagner and Altenberg, 1996; Wimsatt and Schank, 2004), help to make sense of how both types of causality often underlie nested hierarchies. Bechtel (2011) has furthermore called this a form of cyclic causality, but explanation-wise, he continues to understand cyclic causality as reducible to a primary upward form of causality (Craver and Bechtel, 2007; for a discussion, see Gontier, forthcoming).

Finally, most nested evolutionary hierarchies are currently based upon natural selection theory, but the Extended Synthesis has demonstrated that there are many evolutionary theories that provide criteria that we can use to order or depict causality between units and levels. Based upon Dawkins' and Hull's notions of replicators and interactors, Eldredge (1985), for example, has differentiated between a replicator based, genealogical hierarchy and an interactor-based ecological hierarchy. The former highlights how genes as replicators bring forth the germ line (individuals), that bring forth demes (an interbreeding group of organisms), that bring forth species, etc. And the ecological hierarchy represents how, in their nonreplicating aspects, genes constitute interacting cells that build soma that build populations that build communities, and these exchange much more that an informational genetic code amongst them in the economy of nature (Tëmkin and Eldredge, 2015). As we shall see, many more criteria can be used to order units and levels into hierarchies, including chronological and developmental criteria, and these hierarchies provide insights into how we can conceptualize causality and how we can understand mechanisms.

It follows that hierarchies too can be conceptualized in a plurality of ways, and all help to describe and explain ongoing processes in the world (which links the epistemology to ontology). Choosing amongst hierarchies therefore depends upon what (aspects of) phenomena we seek to describe and explain. And this again adds complexity to our subject matter, because we now also must investigate, not only how units and levels interact within a specific hierarchy, but also how units and levels of one hierarchy interact with units and levels of other such hierarchies. It follows that causal explanations cannot only be linear, because there often exist factors that perturb an otherwise linear sequence of events (up or down the hierarchy) from the outside. And this brings forth the non-linear dynamics so typical of interactional hierarchies. In addition to investigating how phenomena are arranged in space and time, interactional hierarchies also help to conceptualize how phenomena occur at different time intervals, and how distinct phenomena and even distinct hierarchies interact, something which can only be made sense of in a three- or more dimensional scalar vector space (for a full discussion, see Gontier, forthcoming). And this in turn implies a conceptual change in how we traditionally define mechanisms.

In short, units and levels always form part of a hierarchy, and in the extensional definition of a mechanism given above, what is meant with the "means or conditions whereby evolution (of units at levels) occurs", is the identification of these different types of causality and the delineation of the processes, in a two-, three-, or multidimensional hierarchy or vector space. In cases of evolution by means of natural selection, for example, these processes are captured by Campbell's heuristic and Lewontin's logical skeleton, described above, and causal directionality is traditionally understood as upward and linearly 
consecutive. But epigenetics and theories on evolvability or inclusive inheritance are best understood as examples of cyclic up- and downward causality.

\subsection{Consequences of $A E E$}

AEE necessitates a pluralistic stance on units, levels, mechanisms and hierarchies, and it follows that there exist different kinds of evolution. The history of evolutionary science is filled with polemic debates on what the true units and levels of evolution are, which diagram is best able to capture how units and levels structure into a hierarchy, what type of hierarchy we should use to understand causation, which mechanisms are best able to explain the evolution of the units and levels, and how the levelling up in a hierarchy occurs. The above demonstrates that the time has come to recognize unit, level, mechanism and hierarchy pluralism.

From this follows that there exist different kinds of evolution, which is the final premise (based upon empirical data) whereon AEE builds. Evolution by means of natural selection occurring in a genealogical hierarchy simply differs from how evolution occurs by means of evo-devo and epigenetics in a developmental or ecological hierarchy. And as adherents of geneculture coevolutionary theories have demonstrated, sociocultural evolution can differ from how biological evolution proceeds.

\section{AEE and language (evolution)}

How then, can we implement AEE into language (evolution) studies? The good news is that this endeavor need not start from scratch, because though (evolutionary) linguists rarely make explicit use of AEE jargon, a brief review of the literature easily enables us to list a set of possible units, levels, and mechanisms of language (evolution), as well as hierarchies (including hierarchical networks) whereby we can conceptualize their interrelation.

In this part, we first distinguish between content- and discipline-based hierarchical divisions (Section 4.1), and then we investigate how major research lines engaged in studying (the biological origin of) language, the structural form of language, the sociocultural dimensions associated with language use, and the diaspora of language/s have conceptualized units, levels/ hierarchies and mechanisms differentially (Section 4.2). We end this part by providing a tentative ordering of the data based upon the premises of AEE (Section 4.3).

\subsection{Content- and discipline-based hierarchical divisions and interactions in language (evolution) studies}

For centuries, scholars interested in language have distinguished (1) the individual language faculty/capacity from (2) the sociocultural group phenomena associated with language use, and (3) the languages actually or previously spoken and signed by mankind. In traditional linguistics (Table 4), the first research avenue is classically associated with biolinguistic investigations into the nature of the individual, human language capacity. The second branch is associated with fields such as sociolinguistics and anthropological linguistics where scholars investigate the sociocultural group phenomena that relate to language use and language formation, and the sociopolitical influence that language communities have on regime or worldview formation. The third avenue involves synchronic research on the structural form of contemporary languages, and diachronic research on the historical origin, relatedness, variation, diaspora and death of the world's languages.

Table 4

A comparison between traditional and Evolutionary Linguistics.

\begin{tabular}{|c|c|c|}
\hline Subject areas/hierarchy & Traditional research fields & Evolutionary research fields \\
\hline $\begin{array}{l}\text { Individual capacity for language (neuro-and } \\
\text { anatomical form, cognitive schemes of reaction, } \\
\text { and behavioral patterns) }\end{array}$ & $\begin{array}{l}\text { Traditional, neurocognition-focused } \\
\text { biolinguistics }\end{array}$ & $\begin{array}{l}\text { Evolutionary biology, paleoanthropology, } \\
\text { behavioral (e.g. ethological) and neuro-cognitive } \\
\text { sciences, physiology, evolutionary developmental } \\
\text { sciences and evolutionary } \\
\text { psychology + computational modelling }\end{array}$ \\
\hline $\begin{array}{l}\text { Sociocultural group phenomena associated with } \\
\text { language (language use and formation, } \\
\text { worldview or regime formation) }\end{array}$ & $\begin{array}{l}\text { Sociology and sociolinguistics, and } \\
\text { anthropology and anthropological } \\
\text { linguistics }\end{array}$ & $\begin{array}{l}\text { Primatology, evolutionary developmental biology, } \\
\text { evolutionary psychology, evolutionary } \\
\text { anthropology, evolutionary archeology, } \\
\text { evolutionary ecology and evolutionary } \\
\text { sociology + computational modelling }\end{array}$ \\
\hline $\begin{array}{l}\text { Different languages, their individual structure and } \\
\text { their variation, relatedness, diaspora and death }\end{array}$ & $\begin{array}{l}\text { Structural, synchronic and historical, } \\
\text { diachronic linguistics }\end{array}$ & $\begin{array}{l}\text { Current, evolutionary biolinguistics and linguistic } \\
\text { and cultural phylogenetics + computational } \\
\text { modelling }\end{array}$ \\
\hline
\end{tabular}

Traditionally, synchronic linguistics has furthermore maintained interactive relations with the first branch, i.e. biolinguistics, in so far as it has been assumed that cognition in general, or an assumed language organ in the brain in particular, determines a common structure for all languages. Diachronic linguistics has maintained interactive relations with socio- and 
anthropological linguistics, the second branch, because the sociocultural dimensions of language are often accountable for the death or diaspora of languages.

From a meta-theoretical perspective, this division already lends insight into how language is conceptualized hierarchically (into units and levels), as well as the interactions there exist between the units and levels of the hypothesized hierarchy and the causal relations that are entertained within this hierarchy. Namely, the hierarchy differentiates between language as an individual faculty (a meso-level), language as a sociocultural phenomenon (a macro-level), and language as a system (a microlevel). And this micro-, meso- and macrolevel somewhat mimics the traditional inorganic, organic and superorganic divide. The divisions also lend insight into the different academic research fields involved, and how they are structured hierarchically, which in turn illuminates a common research plan assumed by academics.

All three research avenues have currently found their way into Evolutionary Linguistics that, as the name implies, takes on an evolutionary approach to the above-listed problems. If a common research agenda for this overall evolutionary approach to language is to be formulated, it is characterized by (1) investigating how the neuro-cognitive and bodily organs as well as the behaviors associated with the human capacity for language evolved; (2) examining how individual and group behavior (causally) induce the sociocultural phenomena associated with language; and (3) analyzing how the variation, diaspora and death of the various languages, that are (causally) induced by (1) and (2), can be modelled by making use of evolutionary theories.

The first research avenue nowadays involves a quest for the neuro-and anatomical forms, the cognitive reaction schemes, and the behavioral patterns that enable language, what they are and how, by which mechanisms they evolved. It therefore makes use of paleoanthropological, behavioral (ethological), neuro-cognitive, psychological, developmental, and physiological sciences that help in this identification, and these sciences nowadays all embrace an evolutionary, often NeoDarwinian and/or evolutionary developmental outlook.

The second research avenue makes use of help sciences such as primatology, evolutionary anthropology, evolutionary archeology, evolutionary psychology, evolutionary ecology and evolutionary sociology to investigate how our kind, our primate cousins, and animals in general, create, communicate and transmit socioculturally acquired knowledge.

The third research avenue continues to build on synchronic linguistics and biolinguistics that, today, includes insights from the fields listed under (1). And it continues to build on diachronic linguistics, a field that nowadays includes insights from the fields listed under (2). Data collected by both schools are currently used to reconstruct cultural and linguistic phylogenetics, in the form of tree-and network diagrams (Atkinson et al., 2008; Mendoza Straffon, 2016). Because of crossfertilizations with the field of bioinformatics, these reconstructions of cultural lineages and language families now also implement biological evolutionary theories that investigate the mode (horizontal or vertical mechanisms) and tempo (rate or speed) of evolutionary change as it occurs by selection, drift, hybridization (e.g. language mixing) and punctuated equilibria theory.

In addition, computer simulations are applied in all three domains of research, to test and generate hypotheses (ScottPhillips and Kirby, 2010; Steels and Szathmáry, 2008; Tamariz, 2014).

Here too, we can therefore again find a hierarchical ordering and a network-like typology amongst the members of the hierarchy, not only in the disciplines involved, but also in the means there exist to study language: as an evolved individual faculty, an evolved sociocultural group phenomenon, or as a phenomenon that is, and that changes and evolves over time. From a meta-theoretical perspective, we can say that by taking on an evolutionary approach, there has been a shift in how scholars conceptualize traditional hierarchies (including the inorganic, organic and superorganic), and how they define and search for causation. Under the motto that "nothing makes sense except in light of evolution", causation is found in evolutionary mechanisms. This contrasts with traditional synchronic approaches where the individual language faculty or linguistic traits have been studied from within the cognitive and linguistic sciences, and where causation was found by describing the current state, constraints and affordances brought forth by cognition on language systems. And it contrasts with diachronic approaches where sociocultural phenomena in general and languages in particular were understood as "superorganic" phenomena (Sapir, 1917) that transcend both the individual organism and any current group, and that therefore need to be explained in terms of constraints and affordances brought forth by the sociocultural realm.

Much of current research involves an attempt to translate and investigate these cognitive, linguistic and sociocultural descriptions of before into causal evolutionary explanations. This, of course, is not an easy task, because evolutionary mechanisms are classically defined by biologists, who study organismal form and behavior, by on the one hand looking for causation in genes, which implies a reduction, and on the other hand investigating from within multi-level evolutionary theory, how genes and organisms bring forth groups and species, whether or not there exists downward causation, and how ecological mechanisms perturbate the genealogical hierarchy.

Translating the above to Evolutionary Linguistics implies tackling three main problems:

1. How do we hierarchize these phenomena and their mechanisms in evolutionary terms? Today, for example, the classic individual-group-superorganic divide mimics the organism-group-species divide, which is the genealogical hierarchy most used by evolutionary biologists. But it is interesting to note that a shift has taken place in how scholars understand 
languages. While traditional historical linguists such as Schleicher (1861/2) compared individual languages to biological organisms, current scholars such as Mufwene (2001) or Croft (2000), and by following Ghiselin (1974), are more inclined to understand languages as analogous to biological groups/demes or species (for a discussion, see Frank and Gontier, 2010). This trend is continued by scholars active in linguistic phylogenetics (e.g. Atkinson et al., 2008), where scholars furthermore include higher elements of a Linnaean taxonomy (especially language families) in their language evolution models.

2. Does a mechanism have to be biological in order for it to be evolutionary? In other words, can we reduce cognitive, linguistic and sociocultural mechanisms to biological mechanisms, or is there some emergent autonomy of the former over the latter, which is what adherents of gene-culture co-evolutionary scholars endorse.

3. Considering the Extended Synthesis, which evolutionary mechanisms, biological and/or cultural, can explain the phenomena?

In the next part, we examine how the different schools involved in studying aspects of language (evolution) have tackled these questions.

\subsection{Commonly assumed units, levels, and mechanisms of language and LE}

Major research lines analyzed in this part include classic linguistics and its evolutionary counterparts - especially geneculture co-evolutionary schools, cognitive developmental psychology, the biolinguistic tradition, the classic adaptationist view to language evolution as first proposed by evolutionary psychologists, multi-modal origin theories that combine competing gesture-first and speech-first theories, and investigations into possible protolanguage/s.

\subsubsection{Synchronic and diachronic linguistics and adherents of gene-culture co-evolutionary theories}

In what follows we distinguish early natural history research from synchronic and diachronic linguistics, and its evolutionary counterparts, and we examine how these scholars have defined how units and levels constitute hierarchies, and how they have defined causality and mechanisms.

\section{The 19th century natural history schools}

Natural history schools originated from early linguists and anthropologists wanting to study the natural as opposed to religiously-defined origins of languages and cultures, from biologists investigating the natural history of biological species, and from geologists investigating the natural history of the earth. And these scholars especially, developed linear hierarchies or chronologies of the world's languages and cultures, its biological species, and the earth's strata for which they sought to determine their causes.

Much of early natural history research was what we today call "historicist" (Popper, 1957). Historicism is a term, introduced by Schlegel, to characterize the early attempts of natural history scholars to find "developmental" "laws" in history. It therefore correlates with the rise of "stage" or "phase" thinking (i.e. early hierarchy theory), as well as with "major transition" thinking that explains how change from one phase to another occurs. In linguistic and anthropological research, this translated to scholars trying to find the different historical stages that humans, languages and cultures had gone through, and they mapped language trees onto sociopolitical systems and the various ethnicities that make up the human species. They formulated these developmental theories before the advent of evolutionary thought, but their developmental "laws" can be understood as precursors to attempts at finding mechanisms that induce change.

Smith (1776), for example, distinguished between 4 societal stages going from hunter-gathering to pastoralism, agriculturalism, and commerce/industrialism. Blumenbach (1780), though pleading for a unity of mankind, distinguished the human species into 5 types; Caucasians, Mongolians, Malayans, Americans, and Ethiopians, a distinction that later would be adopted by racial theories. Comte (Martineau, 1865), one of the founders of the field of sociology, argued that human thought and knowledge had transitioned from a theological stage (characterized first by fetishism/totemism, then polytheism, and later monotheism), over a metaphysical to a positivist/scientific stage. And early moral philosophers and historical linguists of the 19th century, such as von Humboldt (1836), Farrar (1860), and Schleicher (1861/2) did not follow the synchronic/ diachronic research divide as we know it today. Instead, they investigated from which bodily organs a "primordial" language in a natural state might develop, what structure such a hypothesized "urlanguage" might take on, and how such an urlanguage developed, spread and diversified amongst the world's ethnicities.

With the advent of evolutionary theory, these ideas were "evolutionized", the chronologies were transformed into bifurcating trees, and developmental "laws" would steadily transition into mechanisms of evolution. For Schleicher, who endorsed Darwinian evolutionary theory, specific languages were analogous or identical to biological organisms (what biologists and philosophers call "natural kinds" or "biological individuals"), and language families were compared to biological species and genera. He understood his phylogenetic reconstructions of the Indo-European language family as genealogical, and, like Darwin (1859), he understood language evolution as exemplar of how evolution by means of natural selection occurs. Haeckel (1874), inspired by Darwin, drew the first real rather than hypothetical phylogenies or trees of life of biological 
species and higher taxa (including genera, clades and kingdoms), and he found inspiration for his tree diagrams in Schleicher's language phylogenies. He would furthermore compare Schleicher's genealogy of the Indo-European language family to hypothesized genealogies of human "races" (for a discussion, see Gontier, 2011).

With the rise of "social Darwinism", scholars would simply take over existing work on the natural history or genealogy of languages and try and map these onto the hypothesized societal and cultural types or stages. This resulted in semiscientific or pseudo-scientific theories that were often ill-founded and racist. Haeckel, for example, formulated his biogenetic law that ontogeny recapitulates phylogeny and that new features are added by terminal addition. Morgan (1877) argued that humans went from a savage over a barbarian to a civilized state and he applied evolutionary theory to justify these claims. The linear chronologies that they developed were considered necessary for "developmental progress" to occur, and other cultures and languages, were often considered to have "regressed" or "degenerated" when compared to western societies. And Max Müller (1866) critiqued early, philosophical social contract theories on the origin of language calling them "Bow-wow", "Pooh-pooh", "Ding-dong" and "Yo-he-ho" theories, but he too endorsed historicist thinking because he conjectured that especially religious thinking had gone through stages of natural, physical, anthropological and theosophical thinking.

In 1866, the French linguistic society banned publications of such speculative evolutionary theories of language and it banned attempts to construct or reconstruct "universal" (logical) languages. The latter was a remnant of searching for the Adamic language or creating a "lingua franca" such as Esperanto, for example, that could function as an Adamic unified language for humankind (Gontier, 2009). With Ferdinand de Saussure (2006), who is considered the founding father of classic linguistics, synchronic language research was distinguished from diachronic language research. This distinction was not so much inspired by the ban but by the sociological works of Durkheim (1922).

Early "social Darwinism" was also countered in anthropological schools, especially by American anthropologists (of European descent). Going back to Kant (and Hume), American anthropologists endorsed the idea of a "psychic unity" of mankind, and especially Boas (1924) would furthermore link this to "the faculty of language". All humans were said to share a "universal" "common reason" and "common sense". This implies that all men have the same neurocognitive constitution and the same sense apparatus, a premise that is still endorsed today by psychologists and neuro-cognitive scientists, at a biological level. These views enabled to rid scientific thinking of false racial theories, and especially American anthropologists would furthermore counter the racial theories as they developed in the biological sciences, pleading instead for an independent study of culture. Kroeber, for example, would argue that the study of culture is inherently different from the study of biological life, which caused for a decoupling of cultural and linguistic studies from biological/evolutionary ones. Because different languages were understood to create different worldviews (think of Foucauldian "regimes", or Kuhnian "paradigms"), and thus different sociocultural realities, Sapir (1917, 1959), would understand both languages and cultures as part of a man-made "superorganic structure". This superorganic structure is an ontological layer or reality that surpasses the biological realm, and that therefore surpasses the explanatory scope of Darwinian and Neo-Darwinian evolution. For that reason, evolutionary theory was considered to be inapplicable to understand the natural genealogy of cultures and languages. Subsequently, internal reconstruction methods or comparative morpho-syntactic and lexical research that underlie the formation of languages trees that enable research on the historical origin and relatedness of the various languages, became decoupled from research into the origin and evolution of mankind. And terms such as evolution became replaced with a jargon that emphasized "diffusion", "historical particularism" and "incommensurability" of languages and cultures.

But it is intriguing to find out why diffusionist studies on cultural and linguistic variation, developed by scholars such as Kroeber or Sapir, were understood to be fundamentally different from behavioral variation studies and studies on migration or biogeographical diversity as it developed in evolutionary biological schools of thought. When early anthropologists introduced their theories, evolutionary biologists were engaged in founding the Modern Synthesis. And as we saw under Section 3.1, this Modern Synthesis focused on how variation comes about genetically, and how genetic information becomes transmitted vertically, across populations through time. Scholars such as Kroeber considered such vertical descent theories to be inapplicable to understand the natural genealogy or history of the superorganic, because they pointed out that during their diffusion, cultures and languages undergo extensive borrowing and contact, and these interactions or horizontal transfers of information were, at the time, not recognized to characterize the evolution of life or sociocultural phenomena (Gontier, 2007, 2016a).

\section{The 20th century diachronic/synchronic divide}

The synchronic/diachronic divide in classic linguistics and anthropology continues to make use of the classic inorganic, organic, superorganic divide. These classic schools often applied system theoretical views, and therefore focused on describing the hierarchies, by finding recurring patterns that lend insight into the constraints and affordances of a system. And it is these ideas that are currently being "evolutionized" in gene-culture co-evolutionary theories, because the latter want to investigate how the linguistic, social, cultural and political factors or mechanisms put forth by older generations, can be replaced and causally explained by biological and cultural evolutionary mechanisms. We first analyze how these scholars have defined units and levels, and then turn to how they have defined mechanisms (Table 5 , part 1). 
Table 5a

Examples of commonly assumed units, levels, and mechanisms involved in LE (part 1).

\begin{tabular}{|c|c|}
\hline Research line & Units \\
\hline $\begin{array}{l}\text { Synchronic and diachronic } \\
\text { linguistics and adherents of } \\
\text { gene-culture or co- } \\
\text { evolutionary theories }\end{array}$ & $\begin{array}{l}\text { - Language capacity: see biolinguistics } \\
\text { - Language system/universals: } \\
\text { - (symbol) morphology (e.g. vowels, conso- } \\
\text { nants and syllables, words and verbs, pre- } \\
\text { fixes or affixes, ...) } \\
\text { - syntax typology (e.g. subject-verb-object } \\
\text { positioning) } \\
\text { - semantics } \\
\text { - Language phenomenon: } \\
\text { - Linguemes (units of linguistic structure and } \\
\text { their manifestations, e.g. utterances) } \\
\text { - Idiolect (cognition based) } \\
\text { - Dialect (socioculturally-defined, e.g. by } \\
\text { class or division of labor; ecologically- } \\
\text { defined, e.g. by geographical distribution) } \\
\text { - Sociolect (group-based, and groups are } \\
\text { defined based on age, gender, ethnicity, etc.) } \\
\text { - Language }\end{array}$ \\
\hline
\end{tabular}

Levels/hierarchies

- Intra-linguistic levels (based • Non-evolutionary

upon recognized structural

divisions, e.g. morphology, syntax, ...)

- Inter-linguistic levels (based

upon recognized classifications of language families

that mimic Linnaean hierarchies)

- Spatiotemporal levels where the phenomena occur:

- In time: historically, e.g. timeline based

mechanisms: e.g. Linguistic, social, cultural and political factors, processes and mechanisms underlying culturohistorical change

- Often formulated in cultural ecological, diffusionist jargon

- Evolutionary mechanisms:

- Hull's (1980) universal selection scheme (applied by e.g. Croft, 2000)

- In space: ecological, envi- • Cultural evolution as defined ronmental levels:

- geographical distributions

- sociocultural ecology:

- Individual

- Group

- Community by Lewontin's (1970) universal skeleton of natural selection (applied by e.g. Mesoudi, 2016)

- Cultural evolutionary mechanisms (Boyd and Richerson, 1985; Deacon, 1997; Dediu et al., 2013)

- Biological and sociocultural levels where the phenomena evolve:

- Individual/idiolect

- Group/dialect

- Community/sociolect

- Learning mechanisms (Tamariz, 2014; Scott-Phillips and Kirby, 2010)

- Drift (Bentley et al., 2011; Reali and Griffiths, 2010), punctuated equilibria (Atkinson et al., 2008; Gray et al., 2009; Gray and Jordan, 2000), and reticulations (Croft, 2000; Nelson-Sathi et al., 2010)

- Often formulated in geneculture co-evolutionary theories, as Complex Adaptive Systems approaches, or from within macroevolutionary, linguistic phylogenetics

Early cognitive developmental - Piaget's cognitive units:

psychology (Piaget, Vygotsky \& Campbell) "sensori-motor" (action-scheme based) => "preoperational" (symbolic) $=>$ "concrete operational" (logical) and => "formal operational" (mental) stage
- Biological-cognitivesociocultural

- Vygotsky's zone of proximate development
- Biological mechanisms: natural selection, early evodevo and epigenetics

- Cognitive mechanisms: assimilation and accommodation, learning

- Universal selection operating through blind variation and selective retention

- Vicarious selection

Synchronic linguistics has resulted in a better understanding of language as a system, and it has been able to identify linguistic universals. Linguistic universals are traits or features that are shared by all languages (Greenberg, 1963; Comrie, 1989). Examples include the presence of symbols (words or signs), syntax (e.g. Subject-Verb-Object positioning, with a worldwide dominance of SVO or SOV positioning) and semantics. These can be understood as units of language (evolution). Synchronic linguists have also tried to find universal rules (which are descriptions of recurring patterns) for how these structural aspects of language take shape, and how they provide affordances and constraints upon linguistic systems. And as we saw under Section 3.3.2, such descriptions can already be understood as causal explanations.

Diachronic linguistics have, on the other hand, often identified intra-and inter-linguistically variation in how aspects such as declinations, consonant mutations, etc. come about. And by questioning assumed universal units and patterns, they have investigated language, not as a closed system, but as a phenomenon that occurs within cultural environments, and this cultural ecology can be understood as a level that is dividable into sublevels.

More specifically, the classic sociolinguistic or cultural ecological hierarchy investigates how the phenomenon of language occurs in space and time. When studying languages over time, scholars either make use of chronologies or tree typologies. 
Chronologically, we can differentiate English, for example, based upon how it was spoken in the 18th, 19th, and 20th century. And when investigating language relatedness, scholars have developed tree models.

When studying language in space, scholars either study the geographical distribution of languages (the distribution of American versus British English, for example), or they study language from within sociocultural ecological theory. Ecologically, scholars have often used sociocultural differences including artificial or man-made differentiations based upon class, ethnicity, gender, etc. to develop hierarchies, but in the 19th century, this has often lead to false racial theories. A more common means for hierarchization has therefore been made based upon how language is used differentially by individuals, groups and communities, a differentiation that in turn relates to the idiolect, dialect and sociolect distinction.

Idiolects refer to a single person's language use and the term was first introduced by Bloch (1948) who defined it as the "totality of the possible utterances of one speaker at one time in using a language to interact with one other speaker". The term dialect stems from the ancient Greek dialektos, and refers to the local way wherein people converse in a particular language (and local here refers to geographically distinguishable groups or countries). Dialects therefore refer to conversational or pronunciational differences. Sociolects or group languages refer to group-specific languages, and the groups are not differentiated by geographical barriers, but by sociocultural divisions (class, gender, work, ethnicities). The Dutch linguist, Moerman, who first defined sociolects or "group languages", compared them to secret languages and argued that they stem from an instinctive tendency to differentiate oneself into groups. Moerman (1932, in van der Sijs, 2002, pp. 31-2, my translation): "I think the primordial tendency to separate oneself into groups also leads to language division/separation in one's language. When language is the social bond par excellence, we have to assume that the formation of private groups leads to the formation of group languages". ${ }^{1}$ He furthermore compared the acquisition of a specific sociolect to rites of passage. Today, the sociolect is often used indifferently to refer to how a sociocultural community makes use of a particular language, or it refers exclusively to local group languages that each form part of a larger community.

And this brings us to the different mechanisms that scholars in these research fields invoke to explain language change. Traditionally, these hierarchies have all been formulated from within classic historical, diffusionist and sociocultural sciences, without making use of evolutionary jargon, and often by continuing to adhere to the old inorganic, organic, super organic hierarchical divide. Causality was therefore often found by describing the constraints and affordances given by the hierarchical layers of the phenomena studied, and traditionally, language has often been interpreted to be explanatory either from within the linguistic system itself (synchronically), or by investigating the role of the superorganic on language systems (diachronically, in both time and space). Synchronically oriented scholars have argued for an exclusive upward causation: the structure of language determines the rules of the system. And diachronic linguists have countered this tradition by arguing for an exclusive downward causation, by explaining linguistic change (both over time and in space) as induced by linguistic, social, cultural and political "factors" (i.e. the superorganic) that are independent from biological evolution.

Sapir (1930), for example, has argued that consonant mutations and overall phonetic change can be induced by language morphology. And when studying the spatiotemporal pronunciation of American English, for example, Labov (2001) has argued that phonological vowel shifts occur in chains: when one phoneme becomes pronounced differentially, it often brings forth a cascading effect on other phonemes that will also undergo sound changes. The general "principle" of chain shifting is that "peripheral vowels become progressively less open on the peripheral track and more open on the nonperipheral track." Labov (2001, pp. xiv, my italics).) furthermore calls this "principle" “an explanation," “... that is not a simplified description of events, but rather an account of their antecedent causes."

In mapping these shifts, Labov (2010, pp. 4 and 10), has furthermore taken "gender", "age" and "social class" into account to explain diffusion; and he has divided the "speech community" into an "individual", "group" and "community of practice"-level. In explaining these patterns, he has pointed out "social," "cognitive and cultural factors" (Labov, 2010), and he has argued that

"the central dogma of sociolinguistics is that the community is prior to the individual. This means that, in linguistic analysis, the behavior of an individual can be understood only through the study of the social groups of which he or she is a member. ... language is seen as an abstract pattern located in the speech community and exterior to the individual. The human language faculty, an evolutionary development rooted in human physiology, is then viewed as the capacity to perceive, reproduce and employ this pattern. It follows that the individual is not a unit of linguistic analysis." (Labov, 2010, pp. 7)

These scholars continue to separate language change from language evolution, and in their attempts to find causation, they have pointed toward non-evolutionary, social, cognitive, political factors, causes or mechanisms (understood as process descriptions). In evolutionary terms, scholars would be more inclined to call these principles recurring "trends" or "patterns". And in so far as nothing makes sense except in light of evolution, these social, cognitive and political factors are themselves outgrowths of evolution, which is a classic premise already made by traditional evolutionary epistemology. In other words, accepting an evolutionary worldview implies that there cannot exist anything in this world that did not evolve. And though mechanisms can be cultural, political or cognitive in kind, these mechanisms themselves evolved.

\footnotetext{
1 Original (in Dutch): "Ik meen de neiging zich in groepen af te zonderen, een oerneiging, ook leidt tot afscheiding in eigen taal. Waar taal de sociale band bij uitstek is, daar is a priori aan te nemen dat vorming van particuliere groepen vorming van groepstalen tot gevolg heeft." (Moerman, 1932, in van der Sijs, 2002, pp. 31-32).
} 
For that reason, scholars have become unsatisfied with a mere description of the history, spatial distribution and current structure of cultural and linguistic systems, and they have started to examine how these systems evolved by looking for the evolutionary mechanisms that bring them forth. When looking for evolutionary explanations, we can divide between three research lines. Scholars either develop gene-culture co-evolutionary theories, or they understand languages and cultures as complex adaptive systems, while a third avenue involves the study of language and culture from within macroevolutionary phylogenetics.

Much of current gene-culture co-evolutionary theory (Boyd and Richerson, 1985; Cavalli-Sforza and Feldman, 1981; Deacon, 1997; Lumsden and Wilson, 1981), involves an "evolutionizing" of the classic research avenues, by investigating how existing data and theories can incorporate insights from evolutionary sciences. While the classic scholars deny that language change is evolutionary in kind, adherents of gene-culture co-evolutionary theory have redefined the inorganic, organic, super-organic, by investigating how the biological realm underlies cultural evolution, and how the sociocultural levels evolve independently from biological evolution, by specific cultural evolutionary mechanisms.

Complex adaptive systems theory originally assumed that all evolutionary processes can be explained completely by natural selection theory (Maynard Smith, 1982) and the approach therefore associated with the rise of sociobiology (Wilson, 1975). That is why original game theories and computational modelling thereof, as well as in vivo experiments with humans and robots made use of selectionist jargon, when scholars, for example, tried to model the variation and transmission of memes or linguistic replicators (e.g. Steels, 2006). Today, iterated learning experiments mostly apply Lewontin's logical skeleton of natural selection (Mesoudi, 2016; Scott-Phillips and Kirby, 2010; Tamariz, 2014) to understand cultural transmission at an individual and group level. By taking on a universal selectionist approach, they have come to recognize that not all cultural units are replicators or memes, and that the mode of cultural transmission does not rely on the copying of information, it can also be learned. By recognizing that cultural evolution proceeds differentially from genetic selection, they lean more toward gene-culture coevolutionary theories when they say that cultural evolution is Darwinian but not neoDarwinian (Mesoudi, 2016; Tamariz, 2014). Examining how iterated learning can bring forth complex cultural phenomena furthermore implies a study of cyclic interactions between individuals and groups over time.

Finally, especially scholars working in macroevolutionary-oriented, cultural and linguistic phylogenetics have demonstrated that beyond natural selection, language change displays patterns of drift (Bentley et al., 2011; Chang, 2013; Reali and Griffiths, 2010), punctuated equilibria (Atkinson et al., 2008; Gray et al., 2009; Gray and Jordan, 2000); and reticulations (Croft, 2000, pp. 196-7); Nelson-Sathi et al., 2010). And here, the works of Croft (2000) and Mufwene (2001), for example, can be understood as an attempt to dynamize and "Darwinize" linguistics by interpreting the idiolect-dialect-sociolect as a nested hierarchy, similar to, and corresponding with the individual-group-community levels of language use, and the biological organism-deme-species hierarchy (because they compare languages to species). Similarly, we can reformulate their theories by saying that they endorse a dual causality in their nested hierarchies, that is characterized by up-and downward causation, a type of causality that can also be understood as cyclic. We learn the language we speak from the community, for example, but individuals and groups can also change languages by inventing new words or by changing grammatical rules, and by passing them on to future generations. And these capacities, in turn, are grounded in our biological capacities to learn and transmit cultural information. Especially Croft $(2000,2002)$ has therefore introduced the notion of a lingueme that is similar to Dawkins' replicators and memes, and he has applied Hull's universal natural selection scheme that is based upon the notion of interactors.

\subsubsection{Early cognitive developmental psychology}

The field of psychology has undergone similar developments, and in so far as the language faculty is understood as an outgrowth of cognition, psychology has left an indelible mark on linguistics. In psychology, behaviorist schools of thought were countered by cognitive psychology that continued to phrase human cognition in terms of "stages" or "phases" and "major transitions" that occur between them. Piaget (1971), for example, endorsed that knowledge acquisition goes through several developmental stages, and he distinguished between the "sensori-motor" (action-scheme based), "preoperational" (symbolic), “concrete operational” (logical) and "formal operational” (mental) stage. He argued that each phase bares little resemble to the next. Instead, new stages are characterized by a complete turnover of the way thought develops, leading to qualitative developmental changes.

At first this might appear an example of a linear hierarchy or chronology, but Piaget is best considered as a key figure that enabled the cognitive sciences to transition from linear to nested hierarchies, and his work is demonstrative of early evolutionary developmental theory. This is because Piaget entertained a very dynamic, constructivist point of view on how knowledge originates, because cognitive predispositions (instincts or inborn cognitive schemes of reaction) were considered to entertain a dialectic relation with environmental learning processes. In other words, learning was considered to alter inborn predispositions (instincts or cognitive schemes of reaction), which resulted in creative forms of being that surpass gene-driven biological capacities. Instead of countering his ideas to evolutionary, ethological and behaviorist schools of thought, he saw his theories as an extension thereof, and considered learning and the cognitive reorganizations it brings forth as an adaptation driven by cultural processes. The final intellectual stage was therefore a stage of "metacognition", wherein children become capable of absorbing the sociocultural ideas developed in a superorganic structure. His stages can be understood as early attempts to differentiate the units that change during development. And the idea that an individual's 
cognitive capacities alter through learning that occurs in dialectic relation with the sociocultural environment is a cyclic type of causality (Table 5 , part 1 ).

In accordance with classic ideas, this superorganic structure was considered to differ from instinctive, inborn and biologically-evolved knowledge. In this regard, especially Vygotsky (1986) would argue for a primacy of such a sociocultural environment in causing alterations in cognitive thinking (downward causation), while Piaget argued that thinking naturally developed from one stage to the next (upward causation). The former introduced concepts of a "zone of proximal development" to explain the "internalization" of new knowledge, while Piaget introduced his "assimilation and accommodation" theory, where mental constructs are first assimilated to existing cognitive schemes and later accommodated to incoming knowledge (cyclic causality). Fact is that both investigated how the superorganic structure, that language and its associated phenomena such as intellectual knowledge were understood to be, can become internalized during development by individuals through learning.

Today, this easily translates into ideas on gene-culture co-evolution, niche construction, major transitions, and Piaget's metacognition can even be compared to theories on extended cognition or extended minds.

The first to break with merely describing ontogenetic processes, and who also engaged in finding their evolutionary origins was Donald Campbell, the founder of traditional evolutionary epistemology. Campbell (1960), was a cognitive scientist interested in how cognitive and cultural information varies and how it becomes retained differentially across generations through learning. He argued that it was a historical coincidence that natural selection theory had first been formulated in the biological sciences, and he pointed out the potential a general theory of selection has in explaining the evolution of cultural and cognitive learning processes. That is why he developed the "blind variation and selective retention" heuristic whereby he characterized the conditions or means whereby natural selection, as a mechanism, operates. Such blind or stochastic variation can be genetic in kind, but it can also refer to variation in knowledge processes. Ideas, for example, can be creative inventions of the mind, and as such they are initially "blind" to whether or not they enable us to navigate successfully in the world. It is only in a second phase that these ideas are tested, and depending upon how successful they are, these ideas will either become selectively retained, by the individual or by members of the community, or they will be falsified. Selective retention also does not necessarily imply genetic inheritance, because information can become retained by individuals and groups (in the form of traditions, for example).

Campbell's (1960, 1974a) heuristic of "blind variation and selective retention" therefore enables us to understand knowledge processes such as trial and error learning in Darwinian, evolutionary terms (Skinner, 1986). Such heuristics have enabled natural selection theory to become "universalized," which means that the theory cannot merely be applied to explain the evolution of anatomical form, in its universalized form, it can also be applied to explain the evolution of behavior, cognition, language and culture (Mesoudi, 2016). This also implies that natural selection is not an independent entity, fixed to a certain level of a hierarchy in its operations. Instead, different processes can be characterized to be selective, when they meet the conditions as defined by the heuristic.

Campbell (1974b) was furthermore the person who first defined downward causality, and he was one of the first scholars to recognize that cognition can be embodied, and that all organisms evolved knowledge about the world. And here, he continued to try and find the natural history or genealogy of knowledge, from bacteria to humans. Campbell's phases in knowledge evolution went from non-mnemonic problem solving to vicarious locomotor devices to habit and instinct to visually supported thought to mnemonically supported thought to socially vicarious exploration: observational learning and imitation to language to cultural transmission to science. For Campbell, language was an evolved phenomenon that enables acquisition of knowledge on the social and factual world.

\subsubsection{The biolinguistic tradition}

Phase-thinking eventually resulted in theorizing on "critical thresholds", and especially Lenneberg (1964, 1967) demonstrated that the ontogenetic acquisition of language is determined by such thresholds which were called "critical periods". The scientific jargon applied went back to biological system-theoretical schools of thought, that, in close contact with (nested) hierarchy theories, assumed that lower structures in a biological hierarchy undergo major reorganizations when they surpass critical thresholds to reach a "higher" "level" of biological or sociocultural organization (often measured in terms of complexity).

Table 5b

Examples of commonly assumed units, levels, and mechanisms involved in LE (part 2).

\begin{tabular}{|c|c|c|c|}
\hline Research line & Units & Levels/hierarchies & Mechanisms \\
\hline \multirow[t]{2}{*}{$\begin{array}{l}\text { Biolinguistic program } \\
\text { (Chomsky and co-workers) }\end{array}$} & $\begin{array}{l}\text { FLB-sensory-motor system (e.g. } \\
\text { vocal imitation and invention, } \\
\text { neurophysiology of action- } \\
\text { perception schemes, } \\
\text { discrimination of sound patterns, } \\
\text { biomechanisms of sound } \\
\text { production, and modalities of } \\
\text { language production and } \\
\text { perception) }\end{array}$ & $\begin{array}{l}\text { - I(-internal) language: “organism- } \\
\text { internal environment" containing the } \\
\text { "language organ" in the brain } \\
\text { - E(-xternal) language: the "external } \\
\text { environment" that is divided into } \\
\text { social, cultural, physical and ecolog- } \\
\text { ical layers or realms }\end{array}$ & $\begin{array}{l}\text { - Evo-devo mechanisms that track } \\
\text { geno-to phenotypes (e.g. } \\
\text { regulatory gene systems), and } \\
\text { that explain developmental } \\
\text { constraints and affordances (e.g. } \\
\text { Berwick and Chomsky, 2016) } \\
\text { - Often formulated in biological } \\
\text { systems theoretical and exapta- } \\
\text { tionist jargon (e.g. Hauser et al., } \\
\text { 2002) }\end{array}$ \\
\hline & & & (continued on next page) \\
\hline
\end{tabular}


Table 5b (continued)

\begin{tabular}{|c|c|c|c|}
\hline Research line & Units & Levels/hierarchies & Mechanisms \\
\hline & $\begin{array}{l}\text { - FLB-conceptual-intentional } \\
\text { system (e.g. theory of mind, the } \\
\text { ability to acquire non-linguistic } \\
\text { conceptual representations, } \\
\text { referential vocal signals, } \\
\text { imitation, and voluntary control } \\
\text { of signal production) } \\
\text { - FLN (cognitive capacity to Merge } \\
\text { enabling recursion) }\end{array}$ & & \\
\hline $\begin{array}{l}\text { Evolutionary } \\
\text { Psychology }\end{array}$ & $\begin{array}{l}\text { - Hypothesized "brain modules" or } \\
\text { "neural circuits specialized for } \\
\text { specific adaptive problems } \\
\text { (Cosmides and Tooby, 1997) } \\
\text { - Hypothesized "social contract al- } \\
\text { gorithms" (Cosmides and Tooby, } \\
\text { 1997) } \\
\text { - Hypothesized "language" genes } \\
\text { (Pinker and Bloom, 1990) } \\
\text { - Hypothesized "grammar rules" } \\
\text { (Pinker and Bloom, 1990) }\end{array}$ & $\begin{array}{l}\text { - Individual (genes, brain, cognition, } \\
\text { anatomy, behavior) } \\
\text { - Social group (Dunbar, 1998) } \\
\text { - EEA or "environment of evolutionary } \\
\text { adaptedness", which "is not a place or } \\
\text { time. It is the statistical composite of } \\
\text { selection pressures that caused the } \\
\text { design of an adaptation. Thus, the } \\
\text { EEA for one adaptation may be } \\
\text { different from that for another." } \\
\text { (Cosmides and Tooby, 2007) }\end{array}$ & $\begin{array}{l}\text { - Natural selection } \\
\text { - Often formulated in adaptationist } \\
\text { jargon, that assumes "design" }\end{array}$ \\
\hline
\end{tabular}

It is at this moment that Chomsky $(1965,1972)$ entered the scene, and inspired by sociological systems theory and the overall neurocognitive turn in psychology, he continued to understand language primarily as a synchronic formal and structural system that needs to be understood in and of itself. He criticized instructionst schools of thought and made room to study the biological capacity to develop language, ontogenetically, as a neuro-cognitive organ which he dubbed the language organ. Ontogenetic studies on language development and the biological, neuro-cognitive capacity for language have traditionally been studied from within the field of biolinguistics (Givón, 2002; Haverkort and Stowe, 2002; Jenkins, 2000; Puppel, 1995). Nonetheless, Chomsky emphasized that such neurocognitive language acquisition research differs from research on the formal, logical aspects of language.

These ideas have themselves evolved, and today, biolinguistics also turned evolutionary. Hauser, Chomsky and Fitch's (2002) distinction between the FLB and FLN can be regarded as a search for the different units of the FLB that first evolved separately and that, according to the authors, were later co-opted in the evolution of language. Amongst examples of the FLB-sensory-motor system, the authors included vocal imitation and invention, neurophysiology of action-perception schemes, discrimination of sound patterns, biomechanisms of sound production, and modalities of language production and perception. Examples of the FLB conceptual-intentional system include theory of mind, the ability to acquire non-linguistic conceptual representations, referential vocal signals, imitation, and voluntary control of signal production (Hauser et al., 2002, pp. 1573). And FLN was originally defined as the cognitive, computational capacity that enables recursion (and for a discussion of later revisions to their definition of FLN, see Wacewicz, 2012). All these can be understood as possible units of language evolution (Table 5, part 2).

When looking for explanations, the authors suggest that these phenomena were exaptations (Gould and Vrba, 1998) that became co-opted for language (also see Tattersall, 2014), and they point toward biological systems theoretical approaches as explanatory frameworks that can function as alternatives to the adaption-selectionist point of views. Especially Berwick and Chomsky (2016) nowadays also implement evo-devo mechanisms into their theories on how the assumed "language organ" emerged, and causality-wise, they continue to understand the brain as the focal point for understanding language, both as a system, and as an evolved capacity (and see also Boeckx and Benítez-Burraco, 2014; Bolhuis et al., 2014).

Level-wise, their distinction between the internal and external environment can be understood as attempts to classify these various units into hierarchical systems, and the Hauser et al. (2002) paper furthermore makes mention of a social, cultural, physical and ecological layer, which they did not further define.

\subsubsection{Evolutionary psychologists' adaptationist view on LE (1990)}

Ethology and classic evolutionary biology steadily developed into sociobiology (Wilson, 1975) that developed into the new evolutionary sciences: evolutionary psychology, Evolutionary Linguistics, evolutionary archaeology, and evolutionary anthropology. Today, all these sciences take on an evolutionary and often selectionist point of view. Although biolinguistic, cognitive and instructionist models already embraced biological complex adaptive systems theory, it was two evolutionary psychologists, Pinker and Bloom (1990), that for the first time clearly introduced a selectionist account into research on the origin of language. Their primary goal was to accomplish a synthesis between Chomsky's theories on the human language faculty and Neo-Darwinian, selectionist accounts by arguing that natural selection can lead, gradually, to the evolution of such a complex adaptive system. Inspired by Dawkins (1982, 1983), Pinker and Bloom (1990) stated that language shows “design", and that, therefore, language "must" be an outcome of natural selection, because only natural selection can explain such “complex design". Pinker and Jackendoff (2005, pp. 223), for example, argued that "[...] the language faculty evolved gradually in response to the adaptive value of more precise and efficient communication in a knowledge-using, socially 
interdependent lifestyle"; and that "[...] natural selection remains the only evolutionary force capable of generating complex design, in which a feature of an organism (such as the eye or heart) has a non-random organization that enables it to attain an improbable goal that fosters survival and reproduction [...]" (Pinker, 2003, pp. 24). That language is an adaptation and that it arose for social and communicative reasons is today the most commonly defended idea. It is subscribed to by scholars working within computational linguistics (Steels, 2006; Tamariz, 2014), primatology (Dunbar, 1998), psychology (Tomasello and Call, 1997), and neurology (Arbib et al., 2006; Corballis, 2002; Gallese, 2003).

Evolutionary psychologists in general (Cosmides and Tooby, 1987) and Pinker and Bloom (1990) and Pinker and Jackendoff (2005) have done a great deal in "Darwinizing" linguistics, by conjecturing that selection acts on modules of the brain, on specific genes such as the FOXP2 gene, and perhaps even on grammar rules (Table 5, part 2). These can be understood as conjectured units of selection, but today, the existence of language genes, grammar rules and brain modules, however, is still very much debated.

Level-wise, especially Cosmides and Tooby (2007) introduced a hypothetical "environment of evolutionary adaptedness" which they argued is not a real entity out there, but a "statistical composite" that enables theory formation.

The explanatory power of their theories depends upon the premises they make, often inspired by Dawkins (1982), on the power and nature of natural selection as a mechanism. And here, the Extended Synthesis is demonstrating that that explanatory power of natural selection has often been overestimated, and adaptation or adaptive design is not something that is exclusively brought forth by natural selection.

Being adapted is often defined in terms of being able to survive in a given environment, and it is measured in terms of fitness, by the number of offspring one produces. But beyond by means of natural selection, there exist numerous mechanisms that enable organisms to be adapted to their environment. Anderson (1949) and Stebbins (1959), for example, already demonstrated that hybridization in plants contributes to these plants being more adapted to not only the species-specific environment of their parents, but also to new environments. In other words, hybridization sometimes enables the invasion of new territories and thus an expansion of ecological range. It has also been demonstrated to increase the number of offspring. Sometimes, hybrids are more successful in multiplying than the parental species was. It would be interesting to investigate this as a possible reason for why our species hybridized. Symbiosis too can be understood as an adaptive response to the environment, in this case, consisting of other species, and it often contributes to the overall health of the organism (think of the valuable role our microbiome plays, for example, in maintaining health).

Nonetheless, evolutionary psychologists have by far been the most responsible for the introduction of an overall social turn in language origin and evolution studies, by arguing that any kind of language behavior requires learning and teaching that takes place within a social environment (Dunbar, 1998).

But when comparing the hypothesized hierarchies of units and levels with the ones proposed by classic fields, one cannot help but notice that these have been severely truncated, and classic scholars are therefore most certainly right when they point out that more than a lot is currently being lost in the translation of classically obtained data into evolutionary jargon. This is due to early attempts to synchronize language evolution studies to the evolutionary, genealogical hierarchy that runs from genes to organisms to species, but given the Extended Synthesis, and as demonstrated above, there is no reason to restrict ourselves to merely this hierarchy when we want to examine the evolution of language, or to restrict ourselves merely to the mechanism of natural selection, as was proposed by the Modern Synthesis.

\subsubsection{Speech-first, gesture-first and multi-modal theories on $L E$}

Early comparative psychological work, including attempts to learn sign language and artificial languages such as Yerkish to non-human primates (Gardner et al., 1989; Rumbaugh, 1977), were often inspired by rising fields of psychology (Skinner, 1957) that originally endorsed a behavioristic, instructionist stance. Today, these schools are often criticized for exclusively focusing on the study of behavioral outputs, and not investigating how the brain lies at their origination. Nonetheless, their focus on observing and describing how and when communicative behavior is portrayed in our and other species, during ontogeny, was quite innovative in comparison to linguistic schools of thought that at the time merely investigated languages from a formal point of view, without taking either ontogeny or phylogeny into account. Especially Tinbergen (1963) would furthermore point out that ontogenetic studies are the first entry-points to speculate upon the functions of behavior. For him ontogeny or the study of proximate causes, is a first entry point to study phylogeny and to understand the ultimate, evolutionary causes of behavior.

Comparative and ethological research has brought forth discussions on the modality of language, and classically, there exists a divide between scholars who adhere to gesture-first theories and subsequently study the visual-manual media that underlie gestural languages (Armstrong et al., 1995; Call and Tomasello, 2007; Corballis, 2002; Hewes, 1977; Kendon, 1975; Leavens et al., 2005; McNeill, 1992); and scholars who adhere to speech-first theories and subsequently study the auditoryvocal media that enable speech (Fitch, 2000, 2009; Lieberman, 2007; Juergens, 2002).

These scholars have in particular engaged in finding what can be called anatomical units required for gestural and vocal language (Table 5, part 3). Examples of units of gestural communication include facial expressions (Gaspar et al., 2014) and pointing (Call and Tomasello, 2007; Leavens et al., 2005); and examples of units of vocal communication include the anatomical features that make up the supralaryngeal vocal tract (Fitch, 2009; Lieberman, 2007).

This research also links to the neurocognitive sciences, where scholars examine how the brain controls manual and vocal gestures (downward causation), and how cognition enables us and other primates to conceptualize the meaning of these gestures. In what regards the brain, Gallese (2003) and Rizzolatti et al. (2006), have identified mirror neurons in the premotor cortex in monkey brains, that trigger both during manual and vocal gestures, and they have proven that these brain areas form the homologs of human language-associated areas. And in what regards cognition, scholars have distinguished traits 
including empathy, mimesis, imitation, and mental spatiotemporal travelling, that are examined for how they enable intentional communication (Corballis, 2002; Donald, 1993; Ferretti, 2016). These too can be regarded as units of evolution.

Level-wise, scholars have mostly studied how these units develop and become displayed during ontogeny, at the level of the individual, in our and related species, and how this individual level is influenced and affected by the level of the social group, a level that was introduced by the evolutionary psychologists described above. The individual level is thereby often subdivided into the brain, cognition, anatomy and behavior, that mimics a linear and downward sequence of ontogenetic control, going from the brain to the other subunits.

Table 5c

Examples of commonly assumed units, levels, and mechanisms involved in LE (part 3).

\begin{tabular}{|c|c|c|c|}
\hline Research line & Units & Levels/hierarchies & Mechanisms \\
\hline $\begin{array}{l}\text { Gesture-first or speech-first } \\
\text { and multi-modal } \\
\text { theories on LE }\end{array}$ & $\begin{array}{l}\text { - Gesture-first adherents: e.g. ex- } \\
\text { pressions, (ritualized) gestures, oro- } \\
\text { facial movements including eye } \\
\text { gazing, iconic gestural expressions, } \\
\text { pointing, mirror neurons, cognitive } \\
\text { mechanisms enabling empathy, } \\
\text { mimesis, imitation etc. } \\
\text { - Speech-first adherents: e.g. the SVT } \\
\text { and its sub-components, including } \\
\text { the lips, teeth, palate, tongue, velum, } \\
\text { epiglottis, pharynx, the hypoglossal } \\
\text { canal and its nerves, and the hyoid } \\
\text { bone; the lungs; voluntary vocal } \\
\text { utterances } \\
\text { - Multimodal theories: Both gesture } \\
\text { and speech-related units }\end{array}$ & $\begin{array}{l}\text { - Individual (genes, brain, cognition, } \\
\text { anatomy, behavior) } \\
\text { - Social group } \\
\text { - Visual-Manual media } \\
\text { - Individual (genes, brain, cognition, } \\
\text { anatomy, behavior) } \\
\text { - Social group } \\
\text { - Auditory-Vocal media }\end{array}$ & $\begin{array}{l}\text { - Natural selection } \\
\text { - Evo-devo and epigenetics } \\
\text { - Often formulated in continuity } \\
\text { views because scholars endorse } \\
\text { gradual evolution from non- } \\
\text { human primates onwards) }\end{array}$ \\
\hline $\begin{array}{l}\text { Proto-linguistic } \\
\text { investigations }\end{array}$ & $\begin{array}{l}\text { - Multimodal protolanguage } \\
\text { - Abilities underlying symbolic rep- } \\
\text { resentation (e.g. Bickerton's "pri- } \\
\text { mary representational system" that } \\
\text { underlies concept and word forma- } \\
\text { tion characterized by displacement) } \\
\text { - Abilities underlying social commu- } \\
\text { nication (e.g. Wray and Grace's hol- } \\
\text { ophrases theory that is presumed to } \\
\text { be a precursor to compositional and } \\
\text { recursive syntax) }\end{array}$ & $\begin{array}{l}\text { - See above } \\
\text { - The brain and cognition } \\
\text { - In-group and out-group environments } \\
\text { where social communication takes } \\
\text { place }\end{array}$ & $\begin{array}{l}\text { - Natural selection } \\
\text { - Evo-devo and epigenetics } \\
\text { - Often formulated in discontinuity } \\
\text { views (because restructuring } \\
\text { and/or takeover of older hominin } \\
\text { capacities by modern language is } \\
\text { assumed) }\end{array}$ \\
\hline
\end{tabular}

Mechanism-wise, and following Darwin, these units are often conceptualized to have evolved gradually and continuously from primates onward by means of natural selection, and disputes arise mostly on which primates and hominids displayed what traits, which system evolved first, or when vocal language replaced gestural language on the evolutionary time scale. Evolutionary directionality is therefore mostly linear, and here, causality is understood as upward.

In recent years, scholars have combined both approached into multi-modal origin theories of language evolution (GoldinMeadow, 2007; Leavens et al., 2014; Levinson and Holler, 2014; Wacewicz and Zywiczynski, 2017). Especially Leavens et al. (2014) have demonstrated that primates have more voluntary control over their vocal calls than previously thought, and Levinson and Holler (2014) have subsequently described language as a "multi-layered" phenomenon. On their view, and over time, the language capacity gradually gained new features that were added onto existing features. And when mapping these features onto the hominin evolutionary timeline, they suggest that ritualized gestures were already present in Hominidae, to which was added during the evolution of early Homo what they call an "interaction engine", pointing, and iconic gestural representations. With the evolution of $H$. heidelbergensis, voluntary vocal utterances were added to these existing layers, resulting in modern language in our species.

Such a view embraces unit-pluralism, but it does not, at present, integrate level- or mechanism-pluralism. Scholars should also beware not to understand this line-up as a case of linear progress characterized by replacements or terminal addition (which is how Haeckel formulated his biogenetic law). Instead, much could be gained from adopting a more cyclic view of how these features reinforce one another, and an interactional view of how these traits, that evolve in different hierarchies (developmental, cognitive and anatomical), together bring forth language. Such would also bring multimodal theories more in congruence with how we understand causality today.

\subsubsection{Proto-linguistic investigations}

Gesture- and speech first modalities have also been linked, by scholars such as Arbib et al. (2006), Donald (1993), or Zlatev (2014), to bodily mimesis that they understand as evolutionary precursors to language. Perhaps they even functioned as elements of a protolanguage (Table 5, part 3).

And in what regards the nature of protolanguage, we can distinguish between scholars that investigate how language might have evolved from a primary representation system characterized by distinct symbols lacking syntaxial ordering 
(Bickerton, 1990), and those that investigate how language might have evolved from holophrasic-based social communication strategies focused on conveying complete sets of information (Wray, 1998; Wray and Grace, 2007). The former relates more to the biolinguistic tradition, while the latter focus more on the social turn as it was induced by evolutionary psychologists.

Here too, scholars have made great progress in delineating possible units of language evolution, but research on the levels and hierarchies they form, as well as research on mechanisms often lags behind. Instead, by following evolutionary psychologists, scholars have assumed that all units evolve by means of natural selection, and to a lesser extent by mechanisms studied from within epigenetics and evo-devo, and analyses often remain limited to how these traits might have evolved in social groups.

\subsection{A tentative and pluralistic ordering}

Scholars actively engaged in researching the origin and evolution of language have thus, albeit often implicitly, already tackled questions on the units, levels, mechanisms, the hierarchies they form, and what that implies for the different kinds of evolution there are. Polemic debates held by scholars belonging to these different research lines, however, on which paradigm is more right than the other, or which units, levels and mechanisms are more relevant than the other, have often disabled synthesis, both in what regards the development of a shared research program and a unified theory on how language evolved.

Truth is that all these paradigms have made valuable contributions to how we can understand language evolution, and in Table 6, we provide a tentative ordering of the units, levels and mechanisms that possibly underlie the evolution of language. The levels are furthermore outlined into possible hierarchies that are partly based upon ideas developed within the above detailed research lines.

Table 6

Possible units, levels, evolutionary mechanisms/processes and hierarchies involved in LE.

\begin{tabular}{|c|c|c|}
\hline Units & Levels and hierarchies & Evolutionary mechanisms and processes \\
\hline $\begin{array}{l}\text { Genes and gene clusters } \\
\text { e.g. the FOXP2 gene and the genes regulated by } \\
\text { its transcription factor (i.e. the CNTNAP2, } \\
\text { CTBP1, and SRPX2 genes), ASPM genes } \\
\text { Brain areas that underlie the FLB (Broca, } \\
\text { Brodmann's area 44, 45, Wernicke) and its } \\
\text { sub-components (e.g. modules or specific } \\
\text { neurons such as mirror neurons) } \\
\text { Cognitive capacities } \\
\text { e.g. intentionality, ToM, memory, empathy, } \\
\text { emotions, hand-eye coordination, navigation } \\
\text { in time and space including foresight, goal- } \\
\text { oriented behavior, and planning } \\
\text { Anatomical traits involved in orofacial } \\
\text { movements and gesturing (e.g. the SVT and } \\
\text { its sub-components, hand bones, muscular } \\
\text { structures) } \\
\text { Behavioral capacities } \\
\text { e.g. facial expressions, pointing, co-verbal } \\
\text { gesturing } \\
\text { Linguistic system traits } \\
\text { e.g. displacement, recursion, morpho-syntax } \\
\text { Linguistic phenomena } \\
\text { e.g. linguemes, idiolect, dialect, sociolect, a } \\
\text { specific language } \\
\text { Precursors to language } \\
\text { e.g. protolanguage and its sub-components } \\
\text { Specific languages } \\
\text { e.g. English, French, German } \\
\text {.. } \\
\text { Relates to debates on multi-unit evolution, } \\
\text { debates over whether or not language change is } \\
\text { an aspect of language evolution, and the nature } \\
\text { of ontological hierarchies }\end{array}$ & 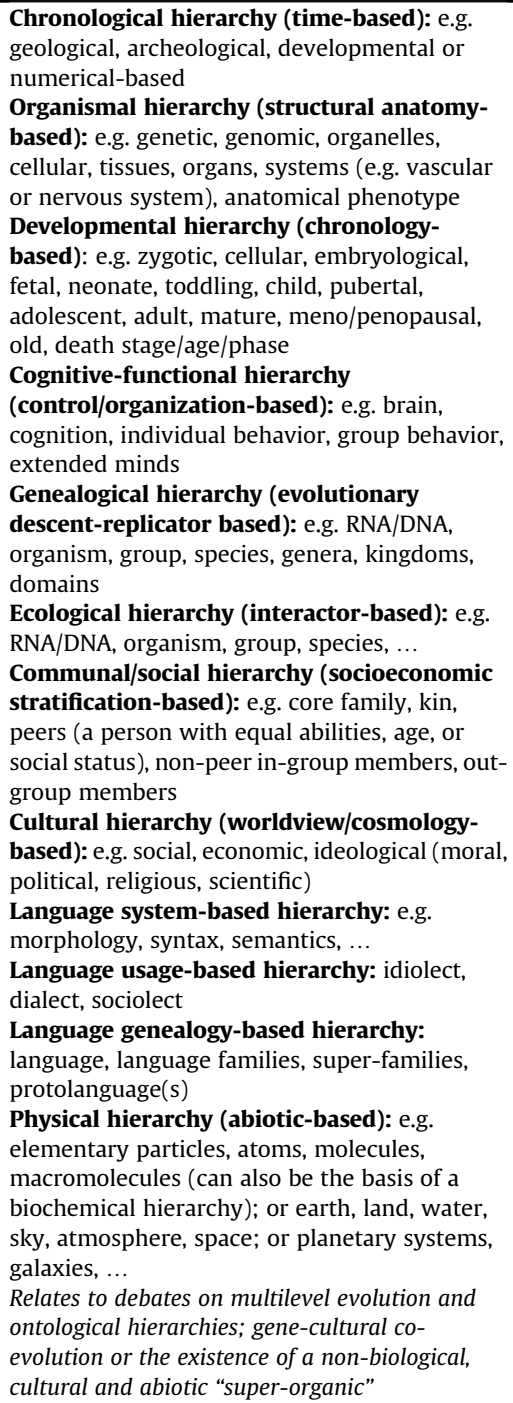 & $\begin{array}{l}\text { Natural selection, Sexual selection, Neutral } \\
\text { evolution/drift } \\
\text { Relates to gradual patterns and discussions on } \\
\text { adaptations/neutral traits/exaptations } \\
\text { Reticulate evolutionary mechanisms } \\
\text { e.g. lateral gene transfer, symbiosis, } \\
\text { hybridization } \\
\text { Relates to interactional patterns, the means } \\
\text { whereby information is transmitted and debates } \\
\text { on the tempo of evolution } \\
\text { Mechanisms of evo-devo and epigenetics } \\
\text { e.g. gene regulatory networks, DNA } \\
\text { methylation, histone modification, ... } \\
\text { Relates to interactional patterns, and phenomena } \\
\text { such as phenotypic accommodation, phenotypic } \\
\text { plasticity, niche construction, ... } \\
\text { Macroevolutionary processes } \\
\text { e.g. the turnover pulse hypothesis, Red Queen } \\
\text { hypothesis, ... } \\
\text { Relates to patterns of punctuated equilibria and } \\
\text { stasis and debates on the tempo of evolution } \\
\text { Physical processes } \\
\text { e.g. climate change } \\
\text { Relates to discussions on the nature of } \\
\text { mechanisms } \\
\text { Cognitive, cultural and linguistic mechanisms } \\
\text { e.g. operant and classic conditioning, } \\
\text { observational learning, imitation, direct } \\
\text { instruction, emulative learning, the Baldwin } \\
\text { effect, ratchet effect, mechanisms or processes } \\
\text { that underlie linguistic universals, ... } \\
\text { Relates to discussions on the nature of } \\
\text { mechanisms }\end{array}$ \\
\hline
\end{tabular}


And in line already with traditional EE, all can be understood as evolutionary in nature.

\section{The AEE-heuristics}

AEE not only enables an ordering of existing data. Given the recognition of unit, level, mechanism and hierarchy pluralism, we require a means to find how these elements relate to each other and combine. AEE therefore provides a research methodology in the form of three heuristics. In Table 7, I give an abbreviated version of the three heuristics, and in the following parts, we give an in-depth analysis of both the level and mechanism heuristics. For an in-depth analysis of the unitheuristic, we refer the reader to Gontier (2017).

Table 7

Abbreviated version of the unit, level, and mechanism heuristics (read from left to right and top-down).

IS X A UNIT OF LE?

? $\quad$ Try to prove that $x$ is a unit of LE (1 example suffices); Go to yes.

\begin{tabular}{ll|l}
$Y$ & Where? Identify the lev- & Not one level found? $X$ is not a unit; Go to no.
\end{tabular}

\begin{tabular}{l|l|l}
$E$ el/s where $x$ evolves & One/multiple level/s? How, by which mechanism/s did $x$ evolve?
\end{tabular}

$\mathrm{S}$ (Justification) (Justification)

Since when?

How does $x$ interact with other units? When did $\mathrm{x}$ first originate in time and when did $\mathbf{x}$ become a unit of LE? Is $x$ divisible into one or more sub-or super-units? If so, are they also units in LE?

Is $x$ also a level and/or mechanism?

How relevant is $x$ ?

$\mathrm{N}$ If not a unit, is $\mathrm{x}$ a level

0 and/or a mechanism?

? and yes: Go to the level and/or mechanism-heuristic.

Is $x$ sufficient and/or necessary for LE or for theories thereof?

? or Yes: Go to the level and/or mechanism-heuristic.

No: Is $x$ a window of LE? $\quad$ Yes: Treat $x$ accordingly.

No: Treat $x$ as irrelevant for LE.

IS X A LEVEL OF LE?

? $\quad$ Try to prove that $x$ is a level of LE (1 example suffices); Go to yes.

Y How many/what units $\quad$ No units are identified? $X$ is not a level; Go to no.

E evolve at $x$ ?

$S$

What is the ontological

status of $x$ ?

Since when?

One/multiple unit/s? (Justi- By which/How many evolutionary mechanisms did the fication) unit evolve at $\mathrm{x}$ ? (Test)

Is $\mathrm{x}$ an abstract notion that facilitates theory formation, or an existing entity?

How does $x$ interact with

Locate the origin of $\mathrm{x}$ in time or indicate when it becomes necessary to invoke $\mathrm{x}$ as an abstract notion in LE theories.

other levels?

Is $x$ also a unit and/or

mechanism?

How relevant is $x$ ?

$\mathrm{N}$ If not a level, is $x$ a unit

0 and/or mechanism?

Is $x$ divisible into sub-or super-levels?

If so, are they also levels in LE?

? and yes: Go to the unit and/or mechanism-heuristic.

Is $x$ sufficient and/or necessary for LE or for theories thereof?

? or Yes: Go to the unit and/or mechanism-heuristic.

No: Is $x$ a window of LE? Yes: Treat $x$ accordingly.

No: Treat $x$ as irrelevant for LE.

\section{IS X AN EVOLUTIONARY MECHANISM OF LE?}

? $\quad$ Try to prove that $\mathrm{x}$ is an evolutionary mechanism involved in LE; Go to yes.

$Y$ On how many units is $x$

E active?

$\mathrm{S}$

How does $\mathrm{x}$ work?

Since when?

How does $x$ interact with

other mechanisms?

Is $x$ also a unit and/or lev-

el?

How relevant is $x$ ?

$\mathrm{N}$ If not a mechanism, is $\mathrm{x}$ a

O unit and/or level?
Not one unit: $x$ is not an evolutionary mechanism involved in LE.

One/multiple unit/s. $\quad$ At how many levels is $x$ active? (Test)

(Justification)

What conditions need to be met for $\mathrm{x}$ to occur?

(Requires universal heuristics of the working order of the mechanism.)

Locate in time when these conditions are met regarding each unit and each level.

Is $x$ divisible into sub-or super-mechanism/s?

If so, are they also mechanisms of LE?

? and yes: Go to the unit and/or level-heuristic.

Is $x$ sufficient and/or necessary for LE or for theories thereof?

? or Yes: Go to the unit and/or level-heuristic.

No: Is $x$ a window of LE? $\quad$ Yes: Treat $x$ accordingly.

No: Treat $x$ as irrelevant for LE. 
6. An in-depth analysis of the levels of language evolution

AEE is a methodology that enables a systematic identification, examination and evaluation of units, levels and mechanisms of LE, and knowing these in turn helps us build hierarchies that underlie explanatory theories on LE. In this part, we first give the full version of the level heuristic (Table 8), and then we walk through the heuristic point by point.

6.1. Full version of the level heuristic

Table 8

Is $\mathrm{x}$ a level of LE? (Full Version).

\begin{tabular}{|c|c|c|c|c|c|}
\hline$?$ & \multicolumn{5}{|c|}{ 1. Try to prove that $\mathbf{x}$ is a level of LE (1 example suffices). Thus, go to yes. } \\
\hline $\mathbf{Y}$ & \multirow{2}{*}{$\begin{array}{l}\text { Which/how } \\
\text { many LE } \\
\text { units evolve } \\
\text { at } x \text { ? }\end{array}$} & \multicolumn{4}{|c|}{ 2.a. Not one language unit is found to be present $=>x$ is not a level of $L E$, go to no. } \\
\hline $\begin{array}{l}\mathbf{E} \\
\mathbf{S}\end{array}$ & & $\begin{array}{l}\text { 2.b. One } \\
\text { unit? } \\
\text { Justifies that } \\
x \text { is a level. }\end{array}$ & \multicolumn{3}{|c|}{$\begin{array}{l}\text { 2.b.1. If this unit is a newly identified unit of } L E \text {, investigate this unit from } \\
\text { unit onward. }\end{array}$} \\
\hline & \multirow[b]{2}{*}{$\begin{array}{l}\text { Identify new } \\
\text { units and/or } \\
\text { examine } \\
\text { whether } \\
\text { known LE- } \\
\text { units evolve } \\
\text { at this level }\end{array}$} & \multirow{2}{*}{$\begin{array}{l}\text { 2.c. Multi- } \\
\text { ple units? } \\
\text { Justifies that } \\
x \text { is a level. }\end{array}$} & \multicolumn{3}{|c|}{$\begin{array}{l}\text { 2.c.1. If amongst these units are newly identified unit(s) of LE, investi- } \\
\text { gate these unit(s) from unit onward. }\end{array}$} \\
\hline & & & \multicolumn{3}{|c|}{$\begin{array}{l}\text { 2.c.2. How do the different units interact/ relate to one another re- } \\
\text { garding this level in particular? }\end{array}$} \\
\hline & \multirow{2}{*}{$\begin{array}{l}3 . \\
\text { Which/How } \\
\text { many evo- } \\
\text { lutionary } \\
\text { mecha- } \\
\text { nisms are } \\
\text { active at } \\
\text { (not on) } x ?\end{array}$} & \multicolumn{4}{|c|}{$\begin{array}{l}\text { 3.a. The answer depends upon the units that evolve at this level. } \\
\text { Testing device because this equals the question: how many evolutionary mechanisms are } \\
\text { active upon the units that evolve at this level. If there are newly identified evolutionary } \\
\text { mechanisms active upon these units, this will be demonstrated during the examination of the } \\
\text { unit. Identifying one mechanism also confirms that it is justified to call } x \text { a level. }\end{array}$} \\
\hline & & \multicolumn{4}{|c|}{$\begin{array}{l}\text { 3.b. If multiple mechanisms are identified, how do these different evolutionary mech- } \\
\text { anisms interact/relate to one another regarding this level in particular? }\end{array}$} \\
\hline & \multirow{2}{*}{$\begin{array}{l}\text { 4. What is } \\
\text { the ontolog- } \\
\text { ical status } \\
\text { of } x \text { ? }\end{array}$} & \multicolumn{4}{|c|}{ 4.a. The level is an abstract notion that facilitates theory formation. Explain. } \\
\hline & & \multicolumn{4}{|c|}{ 4.b. The level is an existing entity. Prove its existence. } \\
\hline & \multirow{5}{*}{$\begin{array}{l}\text { 5. Since } \\
\text { when? } \\
\text { (Depends on } \\
\text { the age of } \\
\text { the unit(s) } \\
\text { that is/are } \\
\text { identified to } \\
\text { evolve by } \\
\text { (an) evolu- } \\
\text { tionary } \\
\text { mechanism(s) } \\
\text { at that level) }\end{array}$} & \multicolumn{4}{|c|}{$\begin{array}{l}\text { 5.a. Locate the origin of } \mathbf{x} \text { in time (if it is an existing entity) or locate in time when it } \\
\text { becomes necessary to invoke } \mathbf{x} \text { as an abstract notion in LE (or other theories). }\end{array}$} \\
\hline & & \multicolumn{4}{|c|}{$\begin{array}{l}\text { 5.b. Locate in time when } \mathbf{x} \text { became a level of LE } \\
=\text { Locate in time when each } L E \text { unit started to evolve at this abstract or actual level } x \text { (in } \\
\text { case of multiple units: the oldest unit = when } x \text { became a level in } L E \text { ) }\end{array}$} \\
\hline & & \multirow{3}{*}{$\begin{array}{l}\text { 5.c. Has x } \\
\text { constantly } \\
\text { been a lev- } \\
\text { el of LE? } \\
\text { Investigate } \\
\text { for each unit } \\
\text { where it } \\
\text { serves as a } \\
\text { level. }\end{array}$} & 5.c.1.? & \multicolumn{2}{|c|}{$\begin{array}{l}\text { 5.c.1.1. Try to prove that is was inconstantly a lev- } \\
\text { el of LE ( } 1 \text { example suffices). Thus, go to no. }\end{array}$} \\
\hline & & & \multirow{2}{*}{$\begin{array}{l}\text { 5.c.2. No. } \\
\text { Implies that the } \\
\text { unit(s) and/or } \\
\text { evolutionary } \\
\text { mechanism(s) } \\
\text { that are active } \\
\text { on these units at } \\
\text { this level are not }\end{array}$} & \multirow{2}{*}{$\begin{array}{l}\text { 5.c.2.1. Specify in } \\
\text { time when it was } \\
\text { not constantly pre- } \\
\text { sent: } \\
\text { Demonstrate when } x \\
\text { was, was not, or again } \\
\text { became a level for a } \\
\text { certain unit and when }\end{array}$} & $\begin{array}{l}\text { 5.c.2.1.1. Treat each varia- } \\
\text { tion of the level in time as } \\
\text { possibly a different level of } \\
\text { LE. } \\
\text { Thus, start from level onward } \\
\text { for each variation. }\end{array}$ \\
\hline & & & & & $\begin{array}{l}\text { 5.c.2.1.2. Investigate } \\
\text { whether each variation of }\end{array}$ \\
\hline
\end{tabular}


Table 8 (continued)

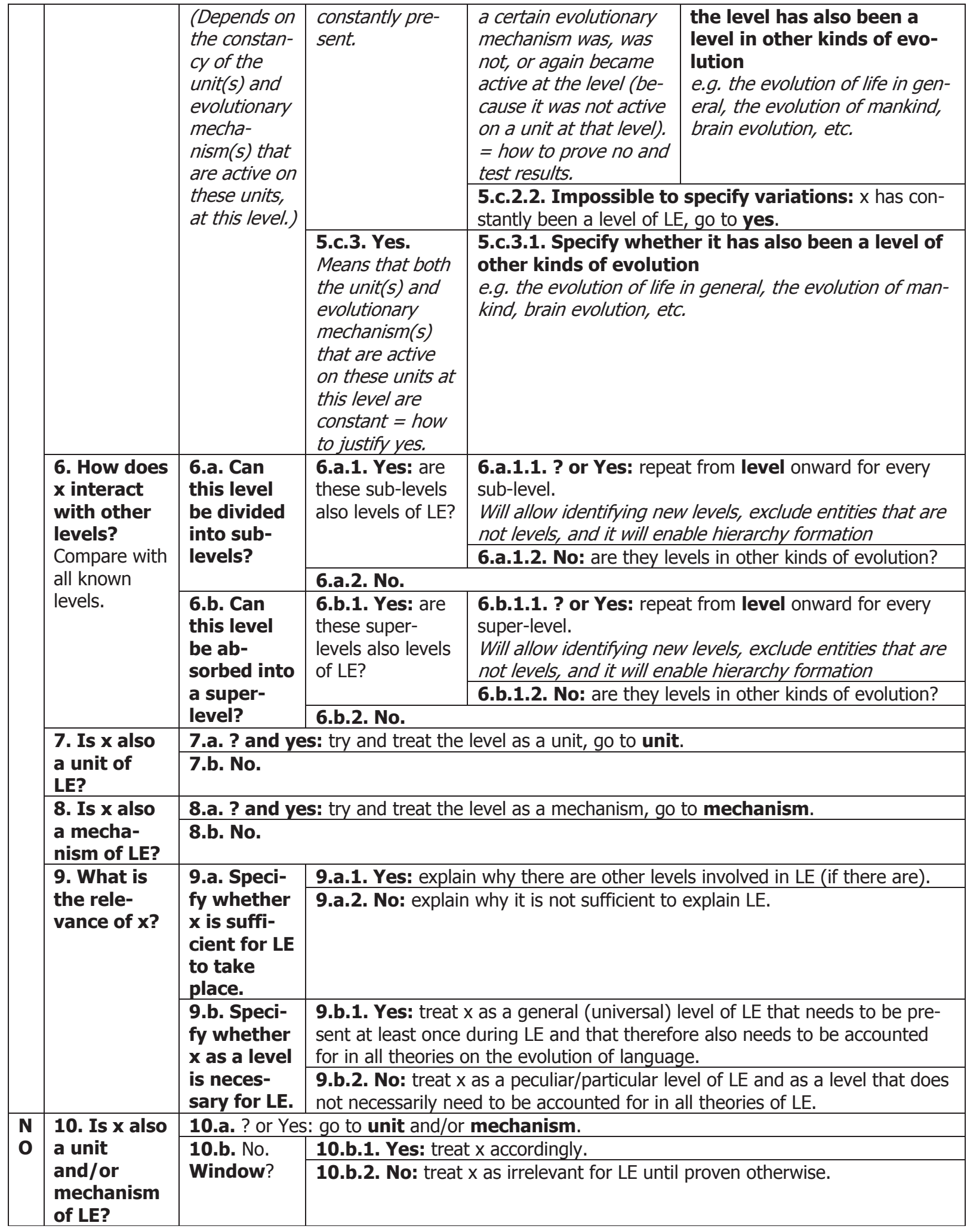


6.2. Walking through the heuristic: how to examine whether $x$ is a level of $L E$

In this section, we walk through the different steps of the heuristic and the numbering here follows the numbering of Table 8. If we have an $\mathrm{x}$ of which we do not know that it is or is not a level of LE, how do we begin examining $\mathrm{x}$ ?

\subsubsection{The question-mark phase}

1. In such an uncertain situation, the heuristic recommends that we try and prove that $x$ is a level of LE. It is not sufficient to try and prove the no path and thus to prove that $\mathrm{x}$ is a unit or mechanism because at least units can also be levels of LE, especially when they are organized into embedded hierarchies. The brain of an individual organism, for example, can be a level where aspects of the faculty of language evolve, but the brain of an individual organism can also be a unit in an extended mind (and note that we here switched between the anatomical, genealogical, developmental and cognitive-functional epistemic hierarchies).

2. How then do we prove that $x$ is a level of LE? $X$ is a level of LE if one or several units of LE evolve by one or several mechanisms at that level $\mathrm{x}$. The main question that is raised in this regard is "how many" units evolve at level $\mathrm{x}$ ?

\subsubsection{The yes phase}

The yes phase is divided into three phases, an identification phase, a question generating and constraining phase, and an evaluation phase.

\subsubsection{The identification phase}

If one immediately chose the yes scenario (2.), this action can be justified only if one or several units of LE can be identified to evolve at this level. If the latter is indeed the case, the goal is to identify all units of LE that evolve at this level.

If not one LE unit can be identified to evolve at $\mathrm{x}, \mathrm{x}$ is not a level of LE, and one can immediately go to no (2.a.). On the other hand, identifying one (2.b.) or several units (2.c.) of LE that evolve at $x$ proves that $x$ is a level of LE.

These units can be identified in two manners. One way is to examine whether $\mathrm{x}$ is or is not a level of LE for each known unit of LE. The other way is to identify new unit(s) of LE that evolve at this level $\mathrm{x}$. In this scenario, the newly identified unit needs to be examined from unit onward (2.b.1.; 2.c.1.). As such, the heuristic is a search engine that allows the identification of new units of LE. If multiple units are indeed identified, it also needs to be specified how these units interact or relate to one another, specifically regarding this level (2.c.2.).

3. The next question that needs to be tackled is how many evolutionary mechanisms are active at, not on this level (3.a.). This question equals the question: how many evolutionary mechanisms enable unit-evolution at this level. The identification of evolutionary mechanisms thus depends upon the units that evolve at this level (because we are looking for process descriptions). These units should in principle have been identified during the previous step of the heuristic, and the identification of the evolutionary mechanisms that are operating at this level $\mathrm{x}$ on one or more units, is a testing device that permits a confirmation of the results that were obtained by following the rules set forth by the previous step of the heuristic. The recognition of one mechanism again confirms that $\mathrm{x}$ is a level. It is advised to independently expose all evolutionary mechanisms that operate at this level, and a simple count of the mechanisms can also provide insight into the nature of the level. If multiple mechanisms are indeed identified (3.b.), a further question that needs to be asked is how these evolutionary mechanisms interact or relate to one another regarding this level in particular. How does the ratchet effect, for example, interact with the Baldwin effect at the cultural level regarding the different units that evolve by these mechanisms?

Note that it is only intelligible to ask how many evolutionary mechanisms are operating at this level, rather than on this level, because if mechanisms are operating on this level, it means that the level is itself a unit of (language) evolution, and then $\mathrm{x}$ needs to be studied as a unit. It is also not legitimate to ask, for example, by which mechanisms this level evolved for this unit. That would be teleological. This question is illegitimate because the existence of the level does not depend upon the existence of the unit. Culture, for example, did not evolve "for" pointing to occur. But pointing can be a unit that evolves at the level of culture, if we can identify mechanisms by which it evolves at this level. And pointing can also underlie cultural practices and thus help construct the cultural niche.

We can also ask when this level becomes a level in the evolution of language. Chimpanzees, for example, have been proven to have cultures, though they do not have human language. Such a cultural realm might have become a locus for language to evolve, and then we can ask when this evolved level became a level specifically involved in language evolution. But this brings us to the since when question (5) and so at this point in the heuristic, the question becomes redundant.

\section{The question generating and constraining phase}

When all these questions are answered, you have identified $\mathrm{x}$ as a level of language evolution. At this point, the heuristic goes beyond the mere mapping or categorizations of levels and provides you with questions that allow you to systematically investigate how $\mathrm{x}$ has evolved. The heuristic is also a question-generating, investigative tool. 
4. The following step in the heuristic involves asking about the ontological status of the level. If something is a unit of (language) evolution, it can be argued to exist, otherwise it cannot evolve. Genes such as the FOXP2 gene, for example, are, under certain circumstances, units of natural selection or drift. The concept of a gene, however, is a theoretical, abstract notion. When a certain group of molecules (nucleotides, phosphates, sugar molecules, etc.) is structured in a certain manner, it is called a gene. When it is said that a gene is the target of selection or when it evolves by drift, one actually argues that it is this whole group of molecules that is evolving. The term "gene" is just an abbreviation for this group of molecules, a handy concept that does not make it necessary to sum up all the different elements that make up the gene. And natural selection too, is an abbreviation of processes characterized by the Darwinian principles. But even though the gene is an abstract notion, the things it denotes are actual, existing entities. While the ontological status of units is somewhat clear, the ontological status of levels is not. Assuming, for example, that "culture" or the "language community" are levels of LE, then the ontological status of these levels is uncertain. Does culture exist independently from the individuals that lie at its emergence (does it form a super-organic structure that has an existence prior to and outside individuals); or is "culture" merely an abstract notion that is introduced to facilitate theory formation? Does there exist a language community without individual language-bearing organisms? How many individuals are required to form one language community? And how many individuals can a language community lose before it is considered a different language community from the original one? These prove to be difficult questions to answer. Nonetheless, the question about the ontological status of the level needs to be raised, and one either needs to explain why it is an abstract notion (5.a.) or prove why it can be regarded as an existing entity (5.b.).

5. Having demonstrated that $x$ is a level of $L E$, it becomes necessary to investigate since when $x$ is a level of LE. When $x$ first became a level of LE (abstract or real) depends upon the age of the unit(s) that is/are identified to be subjected to (an) evolutionary mechanism(s) at that level. The age of the oldest unit that evolves/(d) at that level equals the age that $\mathrm{x}$ became a level of LE.

If $\mathrm{x}$ is an existing entity (5.a.), it can have an existence prior to it being a level of LE. The origin of $\mathrm{x}$ needs to be examined independently, as well as (5.b.) when $\mathrm{x}$ became a level of LE for each unit where it serves as a level. Homologs of Broca's region, for example, already exist in the monkey brain (the F5 region), but it is unclear when this or other homolog structures became a specific level of LE. If $\mathrm{x}$ is not an existing entity, it needs to be demonstrated when it becomes necessary to invoke $\mathrm{x}$ as an abstract notion in the theory of LE; as well as when it becomes necessary to invoke $\mathrm{x}$ as an abstract notion for each unit where it serves as a level. It might also be the case that the level is already invoked as an abstract notion in other theories that relate to theories on LE. For example, the level of culture as an abstract notion might already be invoked in theories on the evolution of humankind or other hominins or hominids, before it is invoked as a level in the evolution of language (e.g. nut-cracking can possibly be learned at a cultural level, in chimpanzee society, prior to intentional pointing).

If the origin of the level has been dated, it should become possible to evaluate if $\mathrm{x}$, from its origin as a level of LE onward, has constantly been a level of LE (5.c.). The constancy of the level $x$ depends upon the constant presence of the unit(s) that evolve at this level as well as the evolutionary mechanisms that are active at this level (on the units). If it is uncertain that $\mathrm{x}$ has constantly been a level of LE, one is advised to try and prove that is was not (5.c.1.). One can try and prove that $\mathrm{x}$ is not a constant level in three ways: one can prove that the units that evolve at this level are not constantly present. Pointing, for example, is not a behavior constantly portrayed in all individuals, and individuals that are motorically impaired can nonetheless learn language without ever being able to point. Or one can try and prove that the evolutionary mechanisms are inconstantly active upon the units that evolve at this level. In one moment in time, the FOXP2 gene might have evolved by drift, in another moment in time, it became positively selected. Or both scenarios might be the case; both the unit and mechanism might demonstrate variation in time. Whether the evolutionary mechanisms are inconstantly active upon the unit(s) is something that can be demonstrated during the independent examination of the units (in agreement with the unit-heuristic). If mechanisms are inconstantly active upon the unit(s), they are inconstantly active at the level where the unit(s) evolves. When such variations can be found, it should be specified when $\mathrm{x}$ has not been a level of $\mathrm{LE}$, and again became a level of LE, for each unit where it serves as a level. And it should be specified when a certain evolutionary mechanism was not active or again became active at the level of LE.

Each variation of the level in time should be treated as possibly a different level of LE from level onward (5.c.1.1.). This is the case because the absence of certain units can affect the level. The absence of humans and their specific types of cognition and tool manufacturing behavior can, for example, change the existing cultural level, and human cultures differ from chimpanzee cultures. These variations should also be examined as levels in other kinds of evolution (5.c.2.1.2.) because it is likely that they extend the realms of language evolution. If it has been impossible to specify variations, $\mathrm{x}$ has been a constant level of LE (5.c.2.2.).

If one skipped the no phase and immediately went to the yes-step (5.c.3.), this action needs to be justified by proving that both the units that evolve at this level as well as the evolutionary mechanisms that are active at this level (on units) are 
constant. In this scenario, one also needs to specify further whether $\mathrm{x}$ has been a level for other kinds of evolution (e.g. the evolution of life in general, the evolution of mankind, the evolution of primates, etc.).

6. The following step of the heuristic involves the examination of how this level interacts with other identified levels. It is interesting to ask if this level can be divided into sub-or super-levels of LE (6.a.; 6.b.) because such enables us to build nested, hierarchical views on how different levels relate to one another. The language community level might, for example, be absorbed into the culture level or divided into the family level, the peer level, the education level, etc. If there are indeed such sub-or super-levels, it needs to be examined whether these levels are also independent levels of LE from level onward (6.a.1.1.; 6.b.1.1.). In this regard, the heuristic is again a level-detecting device. And if such sub-or super-levels are not levels of LE, it is interesting to examine whether they are levels of other kinds of evolution (6.a.1.2.; 6.b.1.2.).

7-8. One also needs to try and identify whether the level under examination is simultaneously a unit (7.) or a mechanism (8.) of LE. That the level $\mathrm{x}$ is also a unit of LE depends on whether it is itself subjected to evolutionary mechanisms that are involved in LE at certain (other) levels of LE. The ontological status of the level might provide a possible break into such investigation. If this is indeed the case, the level should be treated as a unit from unit onward (7.a.). The brain, for example, might be a level where theory of mind evolves, and simultaneously, the brain can also be a (super-)unit of language evolution. In this regard, the heuristic is again a unit-detecting device. It can also be a mechanism-detecting device. To investigate whether a level is also a mechanism, the level x must be demonstrated to work on units at other levels (8.a.). When scholars argue, for example, that culture "drives" language evolution, they not only understand it as a level where language evolution occurs, but as an entity that under certain conditions can inflict change.

\section{The evaluation phase}

So far, the identification of $\mathrm{x}$ as a level as well as the questions that arise from this identification, have allowed you to generate as well as constrain specific research avenues. Now, it is demonstrated how the heuristic also introduces a series of questions that allows you to evaluate the information that is obtained by investigating $\mathrm{x}$ as a level; as well as what role this information can play in a unifying theory of the origin and evolution of language.

9. If $x$ is indeed a level of LE, the final step of the heuristic entails specifying how relevant the level is or has been, in the evolution of language. This will help evaluate the importance of the results obtained when studying this level x, and it will shed light upon what still needs to be examined in the future if one wants to unravel the evolution of language. The relevance of the level can be deliberated by specifying whether $\mathrm{x}$ as a level is sufficient (9.a.) and/or necessary (9.b.) for LE, or both. If $x$ as a level is indeed sufficient for language to evolve (9.a.1.), it should be explained why other levels are involved in the evolution of language (if indeed there are). If it is not sufficient, it should be explained where it falls short (9.a.2.). If $\mathrm{x}$ as a level of $\mathrm{LE}$ is necessary for $\mathrm{LE}$ to occur (9.b.1.), $\mathrm{x}$ should be treated as a general (universal) level of LE that needs to be present during a certain time in LE. In this scenario, $\mathrm{x}$ should also be accounted for in all theories that deal with the evolution of language. If it is not necessary (9.b.2.), $\mathrm{x}$ can be treated as a peculiarity that is neither necessarily present during a certain time in LE, nor need it necessarily be part of a theory that deals with the evolution of language.

\subsubsection{The no phase}

10. If $\mathrm{x}$ is not a level of LE, one needs to investigate whether it is a unit or mechanism in LE (10.a.), or whether it provides a window on the evolution of language (10.b.). Botha $(2003,2006)$ defines windows of language evolution as phenomena not directly involved in the evolution of language that can nonetheless shed light on how language possibly evolved. Current co-verbal gesturing portrayed by infants, for example, in so far as it is portrayed today, was not directly involved in the evolution of language. Nonetheless, co-verbal gesturing might have been involved in the onset of language evolution, and if true, and when adhering to the principle of uniformity, one can extrapolate from the study of current behavior how language might have evolved in the past. In other words, windows are phenomena proximate to language, that enable us to draw inferences on how the capacity possibly evolved. But as such, they possibly differ from actual units, levels, and mechanisms of language evolution, which these heuristics focus on identifying and examining. If $\mathrm{x}$ is such a window, it should be treated accordingly (10.b.1.), and if none of the latter can be proven, $\mathrm{x}$ can be treated as irrelevant for the evolution of language (10.b.2.), until proven otherwise (depending upon incoming information).

\section{An in-depth analysis of the mechanisms and processes involved in language evolution}

We first give the full version of the mechanism heuristic (Table 9), and then we walk through the heuristic point by point.

\subsection{Full version of the mechanism/process heuristic}


Table 9

Is $\mathrm{x}$ an evolutionary mechanism/process in LE? (Full Version).

\begin{tabular}{|c|c|c|c|}
\hline \multicolumn{4}{|c|}{$\begin{array}{l}\text { 1. Try to prove that } \mathbf{x} \text { is an evolutionary mechanism or process involved in LE (1 example suffices). Thus, } \\
\text { go to yes. }\end{array}$} \\
\hline 2. On how & \\
\hline $\begin{array}{l}\text { many units } \\
\text { of LE is } x \\
\text { working? } \\
\text { Identify them } \\
\text { all. }\end{array}$ & \multicolumn{3}{|c|}{\begin{tabular}{l|l} 
2.a. Not one unit found: $\mathbf{x}$ is not an evolutionary mechanism involved in LE. \\
$\begin{array}{l}\text { 2.b. One } \\
\text { unit. }\end{array}$ & $\mathbf{2 . b . 1 . ~ I f ~ t h i s ~ u n i t ~ i s ~ a ~ n e w l y ~ i d e n t i f i e d ~ u n i t ~ o f ~ L E , ~ i n v e s t i g a t e ~ t h i s ~ u n i t ~ f r o m ~}$ \\
Justifies that & unit onward. \\
$x$ is an evolu- & \\
tionary & \\
mechanism & \\
involved in & \\
LE.
\end{tabular}} \\
\hline \multirow{2}{*}{$\begin{array}{l}\text { Examine } \\
\text { whether } x \text { is } \\
\text { active on all } \\
\text { known units } \\
\text { and/or identify } \\
\text { a new LE-unit. }\end{array}$} & \multirow{2}{*}{$\begin{array}{l}\text { 2.c. Multi- } \\
\text { ple units. } \\
\text { Justifies that } \\
x \text { is an evolu- } \\
\text { tionary } \\
\text { mechanism } \\
\text { involved in } \\
\text { LE. }\end{array}$} & \multicolumn{2}{|c|}{$\begin{array}{l}\text { 2.c.1. If amongst these units are newly identified unit(s) of LE, investigate these } \\
\text { unit(s) from unit onward. }\end{array}$} \\
\hline & & \multicolumn{2}{|c|}{$\begin{array}{l}\text { 2.c.2. How do these units interact/ relate to one another regarding this } \\
\text { evolutionary mechanism in particular? }\end{array}$} \\
\hline \multirow{2}{*}{$\begin{array}{l}\text { 3. At (not } \\
\text { on) how } \\
\text { many levels } \\
\text { of LE is } x \text { ac- } \\
\text { tive? } \\
\text { Identify them } \\
\text { all. }\end{array}$} & \multirow{2}{*}{\multicolumn{3}{|c|}{$\begin{array}{l}\text { 3.a. Depends upon the units that are subjected to this evolutionary mechanism at cer- } \\
\text { tain level(s). } \\
\text { Equals the question: the units that are subjected to this evolutionary mechanism, at how many } \\
\text { levels are they subjected to it? One level and more also confirms that it is justified to call x an evo- } \\
\text { lutionary mechanism. } \\
\text { 3.b. If multiple, how do these different levels interact/relate to one another regarding this evolu- } \\
\text { tionary mechanism in particular? }\end{array}$}} \\
\hline & & & \\
\hline $\begin{array}{l}\text { 4. How does } \\
\text { the mecha- } \\
\text { nism work? }\end{array}$ & \multicolumn{3}{|c|}{$\begin{array}{l}\text { 4.a. Which conditions need to be met for the evolutionary mechanism to occur? } \\
\text { Answer requires (universal) EE formulas of the workings of the mechanism. }\end{array}$} \\
\hline \multirow{6}{*}{$\begin{array}{l}\text { 5. Since } \\
\text { when? } \\
\text { Locate in time } \\
\text { when } x \text { be- } \\
\text { came active } \\
\text { on each unit } \\
\text { and at each } \\
\text { level where it } \\
\text { is known to be } \\
\text { active. }\end{array}$} & \multicolumn{3}{|c|}{$\begin{array}{l}\text { 5.a. Locate in time when these conditions are met regarding each unit } \\
=\text { when the evolutionary mechanism became a mechanism involved in } L E \text { at that unit. }\end{array}$} \\
\hline & \multicolumn{3}{|c|}{$\begin{array}{l}\text { 5.b. Locate in time when these conditions are met regarding each level } \\
=\text { when the evolutionary mechanism became a mechanism involved in } L E \text { at that level. }\end{array}$} \\
\hline & \multirow{2}{*}{$\begin{array}{l}\text { 5.c. Has } \mathrm{x} \\
\text { constantly } \\
\text { been a } \\
\text { mechanism } \\
\text { of LE? }\end{array}$} & 5.c.1.? & $\begin{array}{l}\text { 5.c.1.1. Try to prove that is was inconstantly } \\
\text { involved in LE ( } 1 \text { example suffices). Thus, go to } \\
\text { no. }\end{array}$ \\
\hline & & \multirow{2}{*}{$\begin{array}{l}\text { 5.c.2. No. } \\
\text { Means that the unit(s) } \\
\text { subjected to this mecha- } \\
\text { nism are not constant } \\
\text { and/or the conditions that } \\
\text { need to be met are not } \\
\text { constantly present = how } \\
\text { to prove no. }\end{array}$} & $\begin{array}{l}\text { 5.c.2.1. Specify in time when the unit was not } \\
\text { constant and/or when the conditions were not } \\
\text { met (regarding each unit) } \\
=\text { when it was not a mechanism involved in } \angle E= \\
\text { how to prove no. }\end{array}$ \\
\hline & $\begin{array}{l}\text { subjected to } \\
\text { this mecha- } \\
\text { nism and the } \\
\text { constancy of }\end{array}$ & & $\begin{array}{l}\text { 5.c.2. Impossible to specify: } \\
\text { x has constantly been involved in LE. }\end{array}$ \\
\hline & $\begin{array}{l}\text { the condi- } \\
\text { tions that } \\
\text { need to be } \\
\text { met. }\end{array}$ & $\begin{array}{l}\text { 5.c.3. Yes. } \\
\text { Means that the unit(s) } \\
\text { subjected to this mecha- } \\
\text { nism are constant and the } \\
\text { conditions that need to be } \\
\text { met are constantly present } \\
=\text { how to justify yes. }\end{array}$ & $\begin{array}{l}\text { 5.c.3.1. Specify whether it has also been a } \\
\text { mechanism involved in other kinds of evolu- } \\
\text { tion e.g. the evolution of life in general, the evolu- } \\
\text { tion of mankind, brain evolution, etc. }\end{array}$ \\
\hline \multirow{2}{*}{$\begin{array}{l}\text { 6. How does } \\
x \text { interact } \\
\text { with other } \\
\text { mechanisms } \\
\text { involved in }\end{array}$} & \multirow{2}{*}{$\begin{array}{l}\text { 6.a. Can } \\
\text { this mecha- } \\
\text { nism be di- } \\
\text { vided into } \\
\text { sub- }\end{array}$} & \multirow{2}{*}{$\begin{array}{l}\text { 6.a.1.Yes: are these sub- } \\
\text { mechanism(s) also inde- } \\
\text { pendent mechanisms of } \\
\text { LE? }\end{array}$} & $\begin{array}{l}\text { 6.a.1.1. Yes: repeat from mechanism onward for } \\
\text { every sub-mechanism, and explain how they form a } \\
\text { hierarchy }\end{array}$ \\
\hline & & & $\begin{array}{l}\text { 6.a.1.2. No: are they involved in other kinds of evo- } \\
\text { lution? }\end{array}$ \\
\hline
\end{tabular}




\begin{tabular}{|c|c|c|c|c|}
\hline \multirow[t]{4}{*}{$+\frac{1}{2}$} & \multirow[t]{4}{*}{$\begin{array}{l}\text { LE? } \\
\text { Compare with } \\
\text { all mecha- } \\
\text { nisms known } \\
\text { to be involved } \\
\text { in LE. }\end{array}$} & $\begin{array}{l}\text { mecha- } \\
\text { nism(s)? } \\
\text { Depends on } \\
\text { the presence } \\
\text { of sub- } \\
\text { conditions. }\end{array}$ & \multicolumn{2}{|l|}{ 6.a.2. No. } \\
\hline & & \multirow{3}{*}{$\begin{array}{l}\text { 6.b. Can } \\
\text { this mecha- } \\
\text { nism be ab- } \\
\text { sorbed into } \\
\text { a super- } \\
\text { mecha- } \\
\text { nism? } \\
\text { Depends on } \\
\text { the possibility } \\
\text { to combine } \\
\text { different } \\
\text { mechanisms } \\
\text { into one sin- } \\
\text { gle mecha- } \\
\text { nism. }\end{array}$} & \multirow[t]{2}{*}{$\begin{array}{l}\text { 6.b.1. Yes: are these su- } \\
\text { per-mechanisms also } \\
\text { mechanisms of LE? }\end{array}$} & $\begin{array}{l}\text { 6.b.1.1. Yes: repeat from mechanism onward for } \\
\text { every super-mechanism, and explain how they form } \\
\text { a hierarchy }\end{array}$ \\
\hline & & & & $\begin{array}{l}\text { 6.b.1.2. No: are they involved in other kinds of evo- } \\
\text { lution? }\end{array}$ \\
\hline & & & \multicolumn{2}{|l|}{ 6.b.2. No. } \\
\hline & \multirow{2}{*}{$\begin{array}{l}\text { 7. Is } x \text { also a } \\
\text { unit of LE? }\end{array}$} & \multicolumn{3}{|c|}{ 7.a. ? and yes: try and treat the mechanism as a unit, go to unit. } \\
\hline & & \multicolumn{3}{|l|}{ 7.b. No. } \\
\hline & \multirow{2}{*}{$\begin{array}{l}\text { 8. Is } x \text { also a } \\
\text { level of LE? }\end{array}$} & \multicolumn{3}{|c|}{ 8.a. ? or yes: try and treat as a level from level onward. } \\
\hline & & \multicolumn{3}{|l|}{ 8.b. No. } \\
\hline & \multirow{4}{*}{$\begin{array}{l}\text { 9. What is } \\
\text { the rele- } \\
\text { vance of } x \text { ? }\end{array}$} & \multirow{2}{*}{$\begin{array}{l}\text { 9.a. Specify } \\
\text { whether } x \\
\text { suffices for } \\
\text { LE. }\end{array}$} & \multicolumn{2}{|c|}{ 9.a.1. Yes: explain why there are other mechanisms involved in LE (if there are). } \\
\hline & & & \multicolumn{2}{|c|}{ 9.a.2. No: explain why it is not sufficient to explain LE. } \\
\hline & & \multirow{2}{*}{$\begin{array}{l}\text { 9.b. Specify } \\
\text { whether } x \\
\text { is necessary } \\
\text { for LE. }\end{array}$} & \multicolumn{2}{|c|}{$\begin{array}{l}\text { 9.b.1. Yes: treat } x \text { as a general (universal) mechanism involved in LE that needs } \\
\text { to be active at least once during LE and that therefore also needs to be accounted } \\
\text { for in all theories on the evolution of language. }\end{array}$} \\
\hline & & & \multicolumn{2}{|c|}{$\begin{array}{l}\text { 9.b.2. No: treat } x \text { as a peculiar/particular mechanism involved in LE and as a } \\
\text { mechanism that does not necessarily need to be present in all theories of LE. }\end{array}$} \\
\hline \multirow{3}{*}{$\begin{array}{l}\mathbf{N} \\
\mathbf{O}\end{array}$} & \multirow{3}{*}{$\begin{array}{l}\text { 10. Is } x \text { also } \\
\text { a unit } \\
\text { and/or level } \\
\text { of LE? }\end{array}$} & \multicolumn{3}{|c|}{ 10.a. ? or Yes: go to unit and/or level. } \\
\hline & & \multirow{2}{*}{$\begin{array}{l}\text { 10.b. No. } \\
\text { Window? }\end{array}$} & \multicolumn{2}{|c|}{ 10.b.1. Yes: treat $x$ accordingly. } \\
\hline & & & \multicolumn{2}{|c|}{ 10.b.2. No: treat $x$ as irrelevant for LE until proven otherwise. } \\
\hline
\end{tabular}

7.2. Walking through the heuristic: how to examine whether $x$ is an evolutionary mechanism or process involved in $L E$

If we have an $x$ of which we do not know that it is or is not an evolutionary mechanism involved in the evolution of language, how do we begin examining whether this $\mathrm{x}$ is an evolutionary mechanism involved in LE?

\subsubsection{The question-mark phase}

1. If we are not sure, we need to try and prove that $x$ is an evolutionary mechanism that is indeed involved in LE. This can be proven by identifying at least one LE unit that evolves by $\mathrm{x}$. If not one unit of LE is found to evolve by $\mathrm{x}$, then $\mathrm{x}$ is not an evolutionary mechanism (2a). If one $(2 b)$ or several $(2 c)$ such units are indeed identified, it is justified to call $\mathrm{x}$ a mechanism involved in the evolution of language.

\subsubsection{The yes phase}

The yes phase is divided into three phases, an identification phase, a question generating and constraining phase, and an evaluation phase.

\section{The identification phase}

2. If one immediately went to the yes phase of the heuristic, this action can only be justified if at least one unit of LE can be identified that is subjected to this evolutionary mechanism. At this stage, again all units upon which the mechanism is active 
need to be identified (thus, the how many-question prevails). This is done in two ways. One way is to examine whether the mechanism is active/present on all known language units. Another is by identifying new units of LE upon which it is active. If new units have been identified, these need to be investigated separately, from unit onward (2.b.1.; 2.c.1.). Once more, the heuristic can identify new units of LE. If multiple units have indeed been identified, it also needs to be examined how these units interact or relate to one another, specifically regarding this evolutionary mechanism (2.c.2.).

3. The next step is to identify at (not on) how many levels of LE this mechanism is active. This question equals the question at how many levels the identified units of LE evolve by this evolutionary mechanism (3.a.). Thus, in principle, the levels are already identified during the study of the units. Nonetheless, the heuristic advises to sum up the levels independently. This allows to have an independent notion of the number of levels at which the mechanism is active and it enables one to test the previous step. One or more levels again confirm that it is justified to identify the evolutionary mechanism as a mechanism involved in LE. If multiple levels are identified (3.b.), it needs to be examined how these different levels interact or relate to one another, specifically regarding this mechanism.

\section{The question generating and constraining phase}

When these questions are answered, you have identified $\mathrm{x}$ as a mechanism or process of language evolution. At this point, the heuristic goes beyond the mere mapping or categorizations of mechanisms and provides you with questions that allow you to systematically investigate $\mathrm{x}$. The heuristic is again a question-generating, investigative tool.

4. The first question is: How does the mechanism work? More specifically, (4.a.) which conditions need to be met for the evolutionary mechanism to occur? Whether they are active in the evolution of language or in other kinds of evolution, evolutionary mechanisms are not constant forces that are always present. Rather, they only occur when certain conditions are met. These conditions, however, are constant and always need to be met, before an evolutionary mechanism becomes operative. Identifying the conditions that need to be met for a mechanism or process to occur, will be of an evolutionary epistemological nature. More specifically, the answer will involve a universal formula or logical skeleton that is abstracted from the evolutionary mechanism. Such formulas are heuristics that inform us upon the workings of the mechanisms. As we saw, in many cases, mechanisms are simply a set of processes that become substituted with new jargon that we designate as a mechanism, and as such, mechanisms refer to the means whereby elements of a hierarchy interact.

The evolutionary epistemological formulas have presently only been abstracted from two evolutionary mechanisms: natural selection and symbiogenesis. Lewontin (1970) argued that the logical skeleton of selection is differential fitness, inheritance, and selection, while Campbell (1974b) argued that natural selection can be universalized into a blind-variationand-selective-retention heuristic. And symbiogenesis occurs when two independently evolved units merge and create a new individual, the symbiont, which becomes a new unit of evolution (Gontier, 2007).

It will be a challenge for the future to abstract universal formulas from all other known evolutionary mechanisms. Such abstractions that allow identification of the conditions that need to be met for a certain evolutionary mechanism to become active are highly necessary for future theory-formation. And they once again demonstrate how necessary it is to take on a pluralistic stance. It is not because a unit, at one point in time, evolved by means of natural selection, that it cannot evolve by other means at a later point. And given the heterogeneous nature of organisms or languages, it might very well be that different mechanisms simultaneously work on the same or different units and levels. Mechanisms will ideally also become categorized into hierarchies that explain how it is possible that the same evolutionary mechanism is active on one or different units, at the same or on different levels.

5. In LE studies, these conditions need to be specified to be able to answer the question since when a certain evolutionary mechanism became a mechanism particularly involved in the evolution of language. This question can be answered as soon as one can date when the mechanism became active upon each unit and at each level of LE where it is known to operate. But how do we know this? We can investigate when the mechanism became operational by examining when the conditions are met regarding this unit (5.a.). In the case of natural selection, for example, we can try and point out when a unit of LE became a replicator, or when it started to vary blindly and become selectively retained. We can investigate when the mechanism became involved in LE at a certain level of LE by examining when the conditions are met regarding this level of LE (5.b.). Again, in the case of natural selection, this implies identifying in time when a level of LE selectively retains replicators. The latter is again dependent upon the units that evolve at this level.

Afterward, one can also ask whether the evolutionary mechanism $\mathrm{x}$ has constantly, from its identification as a mechanism involved in LE onward, been a mechanism involved in LE (5.c.). The constancy with which the mechanism $\mathrm{x}$ is a mechanism of LE depends on two things: the constancy of the units whereupon it is active: if the unit ceases to exist, the mechanism can evidently not continue to be active upon it. Or, the evolutionary mechanism itself ceases to be active: this happens when the conditions that need to be met for the mechanism to work, seize to be met. If uncertain (5.c.1.) that x has, from its identification as a mechanism involved in LE onward, constantly been a mechanism involved in LE, one again needs to try and prove that it was not (5.c.2.). Proving that it was not (as well as justifying that it was not, if one went immediately to the no phase) equals proving that either the units and/or the conditions that need to be met, are not constantly present (5.c.2.1.). If either one or both scenarios are indeed the case, it needs to be specified in time when variation occurred. If it is impossible to specify when the units that evolve by this mechanism were not present (5.c.2.2.); and/or when the conditions were not present (regarding each unit upon which it is active), $\mathrm{x}$ has been constantly active in the evolution of language 
(5.c.3.). Justifying that the mechanism has been constantly involved in the evolution of language (from its first involvement onward) equals proving that both the units as well as the conditions remain constantly present (5.c.3.). In this case, it also becomes interesting to ask whether the mechanism has been involved in other kinds of evolution, while it was simultaneously involved in LE (5.c.3.1.).

6. The next step in the heuristic entails asking how the mechanism interacts with other mechanisms that are known to be involved in the evolution of language. This is done by comparing the mechanism $\mathrm{x}$ with all other mechanisms that are known to be involved in LE. Although perhaps at first counterintuitive, the mere existence of different mechanisms makes it at least theoretically possible that these mechanisms interact in one form or another, by e.g. competing or being cooperatively or complementarily active upon certain units. From a hierarchical perspective, one can wonder if sexual selection, for example, is a type of natural selection; or whether niche construction, the Baldwin effect, and epigenetic mechanisms, for example, are all types of Lamarckian inheritance. These theoretical possibilities need to be demonstrated to exist or it needs to be explained why they cannot occur in real life. Nonetheless, they need to be the subject of future investigation, and this will enable us to build evolutionary hierarchies, not only of units and levels, but also of mechanisms. For those reasons, the heuristic suggests to investigate whether the mechanism can be divided into sub-mechanisms (6.a.) or super-mechanisms (6.b.). If so, these suband super-mechanisms need to be studied from mechanism onward (6.a.1.-6.a.2.), and it needs to be investigated whether they are also involved in other kinds of evolution (6.a.1.2., 6.b.1.2.). That sub-mechanisms exist depends upon the existence of sub-conditions that can be regarded as single, independent mechanisms. The existence of super-mechanisms will depend upon the existence of mechanisms that allow to combine different mechanisms in a yet to be defined manner (perhaps hierarchically).

7-8. The next step is to investigate whether the mechanism can also be regarded as either a unit (7.) or a level (8.) of LE. The former would entail that the mechanism is itself subjected to at least one evolutionary mechanism recognized to be involved in LE at, at least, one level of LE. The latter would entail that at least one unit of LE can be demonstrated to evolve according to an identified evolutionary mechanism at this mechanism $\mathrm{x}$ or that an evolutionary mechanism is active upon a unit of LE at this mechanism. In so far as mechanisms are an abbreviated way to refer to processes occurring in a lower level of a hierarchy, these processes are real and they can be studied by investigating the movement of the units and levels that underlie the process. It is currently unknown how mechanisms can themselves be the subject of evolution (as units, e.g. can natural selection evolve?) or how they can be levels where (certain types of) evolution occurs (e.g. can the blind variation and selective retention of a phenotype, for example, function as a level for evolution). The first example appears strange, because we think of a mechanism that would make natural selection evolve. But when formulated as our second example, it seems much more plausible. Much depends upon whether or not we reduce mechanisms to autonomous entities or whether we understand them as mere delineations of ongoing processes. The validity of the questions whether evolutionary mechanisms can be units and levels of evolution therefore remains to be proven.

\section{The evaluation phase}

9. Finally, how relevant this evolutionary mechanism is in the evolution of language needs to be examined. This will again allow for an evaluation of the results obtained when studying this mechanism. Supposing, for example, that $\mathrm{x}$ is a mechanism that is identified to be active on all known units, at all known levels, the mechanism will, by and large, have solved the puzzle of how language evolved. The relevance is tested by examining whether the evolutionary mechanism $\mathrm{x}$ is sufficient (9.a.) for LE to occur or not, and whether it is necessary (9.b.) for LE to occur or not. If sufficient (9.a.1.), it needs to be explained why other mechanisms are involved in the evolution of language (if there are); if insufficient (9.a.2.) it needs to be explained why that is so. If necessary (9.b.1.), $\mathrm{x}$ needs to be treated as an evolutionary mechanism that needs to be active at some point during LE and that needs to be accounted for in all theories on the evolution of language. If unnecessary (9.b.2.), the evolutionary mechanism can be treated as a peculiar/particular mechanism that does not need to be active during LE and that does not necessarily need to be accounted for in all theories on the evolution of language. In that case, the inference of the mechanism $\mathrm{x}$ in a theory will depend upon which aspects of LE are highlighted in that theory.

\subsubsection{The no phase}

10. If $\mathrm{x}$ is not an evolutionary mechanism, it needs to be investigated whether it is either a unit or a level in LE (10.a.), or a window on LE (10.b.), and if so, it needs to be treated accordingly (10.b.1.). If neither, $\mathrm{x}$ is irrelevant for the evolution of language until proven otherwise (depending on incoming data, 10.a.2.).

\section{Conclusions and prospects}

Evolutionary Linguistics is a relatively young field, and much of current research involves examining how we can use existing data to explain how language possibly evolved. This requires us to turn this data into an evolutionary framework, and debates have arisen about which evolutionary theories best explain (aspects of) language evolution. It is fair to say that finding answers is a difficult task, one that is by no means facilitated by the current field of evolutionary biology. Evolutionary biologists today are themselves debating the adequacy of the Modern Synthesis, and today, numerous mechanisms of evolution have been introduced that besides natural selection theory explain the evolution of anatomical form. Many of these 
mechanisms still need to become "universalized" before we can objectively apply them to the evolution of behavior, cognition, culture and language. Given that evolutionary mechanisms are on the expansion, and given the complex and heterogeneous nature of language, there is no reason to at present restrict us to mere biological mechanisms of evolution. Gene-culture coevolutionary theorists have long been engaged in finding mechanisms peculiar to cultural evolution, and it is highly likely that language evolution will prove to have some peculiar mechanisms too.

Nonetheless, we can follow the general approach taken by evolutionary biologists, in so far as their work is characterized by finding the units, levels, and mechanisms of evolution, and placing them into evolutionary hierarchies. Here too, it will be a challenge to find the various layers that make up the language capacity, the various languages spoken and signed by mankind, and the sociocultural phenomena that are associated with language; and it will be a challenge to incorporate those into hierarchies.

Nonetheless, any attempt thereat can only be worthwhile because such research enables us to get a better grip on what we know, what needs to be done, and how existing data and theories can combine into unifying theories. The good news is that many scholars, albeit implicitly, have tackled aspects of these questions in one way or another. The heuristics provided here give one way in which we can develop a joint research program.

Implementing these heuristics can only be a joint research endeavor because of the work that needs to be done. In that regard, scholars would highly benefit from online databases that collect information on units, levels, and mechanisms. With so many computational linguists involved in the field, it should not be too hard to set things up. Biologists, for example, have long started to gather their data in such online databases. Nonetheless, we can ask how feasible the approach is because though the questions prove rather simple, providing them with an answer is all but straightforward. And one can ask whether we are ready to tackle the research involved. Nonetheless, we can try, and in so far as bioinformatic approaches enable us to collect and analyze ever-larger datasets, now seems to be a better time than ever before.

\section{Acknowledgements}

This article was written with the support of the Portuguese Foundation for Science and Technology (Fundação para a Ciência e a Tecnologia, grant ID SFRH/BPD/89195/2012 and project number UID/FIL/00678/2013). Cordial thanks go out to Slawomir Wacewicz and Przemyslaw Zywiczynski for inviting me to co-edit this special issue, to the editor-in-chief Sune Steffensen, and to the anonymous referees.

\section{References}

Anderson, E., 1949. Introgressive Hybridization. John Wiley, New York.

Arbib, M., Bonaiuto, J., Rosta, E., 2006. The mirror system hypothesis: from a macaque-like mirror system to imitation. In: Cangelosi, A., Smith, A.D.M.,

Smith, K. (Eds.), The Evolution of Language: Proceedings of the 6th International Conference, Evolang 6. World Scientific, London, pp. 3-10.

Armstrong, D., Stokoe, W., Wilcox, S., 1995. Gesture and the Nature of Language. Cambridge University Press, Cambridge, MA.

Arnold, M.L., 1997. Natural Hybridization and Evolution. Oxford University Press, New York.

Atkinson, Q.D., Meade, A., Venditti, C., Greenhill, S., Pagel, M., 2008. Languages evolve in punctuational bursts. Science 319 (5863), 588.

Bechtel, W., 2011. Mechanism and biological explanation. Philosophy Sci. 78, 533-577.

Bechtel, W., Richardson, R.C., 1993. Discovering Complexity: Decomposition and Localization as Scientific Research Strategies. Princeton University Press, Princeton, NJ.

Bentley, R.A., Ormerod, P., Shennan, S., 2011. Population-level neutral model already explains linguistic patterns. Proc. Biol. Sci. 278 (1713), 1770-1776. Berwick, R.C., Chomsky, N., 2016. Why Only Us. MIT, Cambridge.

Bickerton, D., 1990. Language and Species. University of Chicago Press, Chicago.

Bloch, B., 1948. A set of postulates for phonemic analysis. Language 24, 3-46.

Blumenbach, J.F., 1780. Handbuch der Naturgeschichte, vol. 1. Johann Christian Dieterich, Göttingen.

Boas, F., 1924. Evolution or diffusion. In: Boas, F. (Ed.), 1940. Race, Language and Culture. Macmillan, New York, pp. $290-294$.

Boeckx, C., Benítez-Burraco, A., 2014. Globularity and language-readiness: generating new predictions by expanding the set of genes of interest. Front. Psychol. 5, 1324.

Bolhuis, J.J., Tattersall, I., Chomsky, N., Berwick, R., 2014. How could language have evolved? PLoS Biol. 12 (8), e1001934 http://dx.doi.org/10.1371/journal. pbio.1001934.

Botha, R., 2003. Unravelling the Evolution of Language. Elsevier, Amsterdam.

Botha, R., 2006. On the windows approach to language Evolution. Lang. Commun. 26 (2), 129-143.

Boyd, R., Richerson, P., 1985. Culture and the Evolutionary Process. Chicago University Press, Chicago, IL.

Bradie, M., 1986. Assessing evolutionary epistemology. Biol. Philosophy 1 (4), 401-459.

Brandon, R.N., 1982. The levels of selection. In: Brandon, R.N., Burian, R.M. (Eds.), 1984, Genes, Organisms, Populations. MIT, Cambridge, pp. 133-139.

Call, J., Tomasello, M., 2007. The Gestural Communication of Apes and Monkeys. LEA, Manhaw, NJ.

Campbell, D.T., 1960. Blind variation and selective retention in creative thought as in other knowledge processes. Psychol. Rev. 67 (6), $380-400$.

Campbell, D.T., 1974a. Evolutionary epistemology. In: Schlipp, P.A. (Ed.), The Philosophy of Karl Popper, vol. I. La Salle, Chicago, IL, pp. 413-459.

Campbell, D.T., 1974b. Downward causation in hierarchically organized biological systems. In: Ayala, F.J., Dobshansky, T. (Eds.), Studies in the Philosophy of Biology. University of California Press, Berkeley, pp. 179-186.

Cavalli-Sforza, L.L., Feldman, M.W., 1981. Cultural Transmission and Evolution: A Quantitative Approach. Princeton University Press, Princeton, NJ.

Chang, C., 2013. A novelty effect in phonetic drift of the native language. J. Phonetics 41, 520-533.

Chomsky, N., 1965. Aspects of the Theory of Syntax. The MIT Press, Cambridge, MA.

Chomsky, N., 1972. Language and Mind. Harcourt, Brace, Jovanovich, Columbia University Press, New York.

Comrie, B., 1989. Language Universals and Linguistic Typology: Syntax and Morphology, second ed. Blackwell, Oxford.

Corballis, M.C., 2002. From Hand to Mouth, the Origins of Language. Princeton University Press, Princeton, NJ.

Cosmides, L., Tooby, J., 1987. From evolution to behavior: evolutionary psychology as the missing link. In: Dupre, J. (Ed.), The Latest on the Best: Essays on Evolution and Optimality. MIT Press, Cambridge, MA.

Cosmides, L., Tooby, J., 1997. Evolutionary Psychology: A Primer. http://www.cep.ucsb.edu/primer.html.

Craver, C.F., Bechtel, W., 2007. Top-down causation without top-down causes. Biol. Philosophy 22, $547-563$. 
Croft, W., 2000. Explaining Language Change: An Evolutionary Approach. Pearson, Essex.

Croft, W., 2002. The Darwinization of linguistics. Selection 3 (1), 75-91.

Cziko, G., 1995. Without Miracles: Universal Selection Theory. MIT, Cambridge.

Darwin, C., 1859. On the Origin of Species by Means of Natural Selection, or the Preservation of Favoured Races in the Struggle for Life. John Murray, London.

Dawkins, R., 1976. The Selfish Gene. Oxford University Press, Oxford.

Dawkins, R., 1982. Replicators and vehicles. In: Brandon, R.N., Burian, R.M. (Eds.), 1984, Genes, Organisms, Populations. MIT, Cambridge, pp. 161-179.

Dawkins, R., 1983. Universal Darwinism. In: Hull, D.L., Ruse, M. (Eds.), The Philosophy of Biology. Oxford University Press, New York, pp. 15-35.

de Saussure, F., 1916/2006. Writings in General Linguistics. Oxford University Press, NY.

Deacon, T.W., 1997. The Symbolic Species. W. W. Norton and Co, New York.

Dediu, D., et al., 2013. Cultural evolution of language. In: Richerson, P.J., Christiansen, M.H. (Eds.), Cultural Evolution. MIT Press, Cambridge, MA, pp. 303332.

Donald, M., 1993. Origins of the Modern Mind. Harvard University Press, Cambridge, MA.

Dunbar, R.I., 1998. The social brain hypothesis. Evol. Anthropol. 6 (5), 178-190.

Durkheim, E., 1922. Education et sociologie. Les Presses universitaires de France, Paris.

Eldredge, N., 1985. Unfinished Synthesis: Biological Hierarchies and Modern Evolutionary Thought. Oxford University Press, New York.

Eldredge, E., Salthe, S., 1984. Hierarchy and evolution. Oxf. Surv. Evol. Biol. 1, 184-208.

Farrar, F., 1860. An Essay on the Origin of Language, Based on Modern Researchers and Especially on the Works of M. Renan. John Murray, London.

Ferretti, F., 2016. The social brain is not enough: on the importance of the ecological brain for the origin of language. Front. Psychol 7, 1138. http://dx.doi.org/ 10.3389/fpsyg.2016.01138.

Fitch, W.T., 2000. The evolution of speech: a comparative approach. Trends Cognitive Sci. 4 (7), 258-267.

Fitch, W.T., 2009. Fossil cues to the evolution of speech. In: Botha, R.P., Knight, C. (Eds.), The Cradle of Language. Oxford University Press, Oxford, UK, pp. 112-134.

Frank, R., Gontier, N., 2010. On constructing a research model for historical cognitive linguistics (HCL): some theoretical considerations. In: Winters, M., Tissari, H., Allan, K. (Eds.), Historical Cognitive Linguistics. De Gruyter Mouton, Berlin, pp. 31-69.

Futuyma, D.J., 2010. Evolutionary constraint and ecological consequences. Evolution 64, 1865-1884.

Gallese, V., 2003. The roots of empathy: the shared manifold hypothesis and the neural basis of intersubjectivity. Psychopatology 36 (4), 171-180.

Gardner, A.R., Gardner, B.T., Van Cantfort, T.E. (Eds.), 1989. Teaching Sign Language to Chimpanzees. State University of New York Press, New York.

Gaspar, A., Esteves, F., Arriaga, P., 2014. On prototypical facial expressions versus variation in facial behavior: what have we learned on the visibility of emotions from measuring facial actions in humans and apes. In: Pina, M., Gontier, N. (Eds.), The Evolution of Social Communication in Primates. Springer, Dordrecht, pp. 101-126.

Ghiselin, M.T., 1974. A radical solution to the species problem. Syst. Zool. 23, 536-544.

Givón, T., 2002. Bio-linguistics. John Benjamins, Amsterdam.

Goldin-Meadow, S., 2007. Gesture with speech and without it. In: Duncan, S. (Ed.), Gesture and the Dynamic Dimension of Language. John Benjamins, Amsterdam, pp. 31-49.

Gontier, N., 2007. Universal symbiogenesis: a genuine alternative to universal selectionist accounts. Symbiosis 44, 167-181.

Gontier, N., 2009. The origin of the social approach in language and cognitive research exemplified by studies into the origin of language. In: Pishwa, H. (Ed.), Language and Social Cognition: Expressions of the Social Mind. Mouton de Gruyter, Berlin, pp. 25-46.

Gontier, N., 2010a. Evolutionary epistemology as a scientific method: a new look upon the units and levels of evolution debate. Theory Biosci. 129 (2-3), $167-182$.

Gontier, N., 2010b. How to identify the units, levels, and mechanisms of LE. In: Smith, A., Schouwstra, M., de Boer, B., Smith, K. (Eds.), The Evolution of Language: Proceedings of the 8th International Conference, EVOLANG 8. World Scientific, London, pp. 176-183.

Gontier, N., 2011. Depicting the tree of life: the philosophical and historical roots of evolutionary tree diagrams. Evol. Educ. Outreach 4 (3), 515-538.

Gontier, N., 2012. Applied evolutionary epistemology: a new methodology to enhance interdisciplinary research between the human and natural sciences. Kairos J. Philosophy Sci. 4, 7-49.

Gontier, N., 2013. Pointing and the evolution of language: an applied evolutionary epistemological approach. Humana Mente J. Philosophical Stud. 24,1-26.

Gontier, N., 2015a. Uniting micro- with macroevolution into an extended synthesis: reintegrating life's natural history into evolution studies. In: Gontier, N., Serrelli, E. (Eds.), Macroevolution. Springer, Dordrecht, pp. 227-275.

Gontier, N. (Ed.), 2015b. Reticulate Evolution. Springer, Dordrecht.

Gontier, N., 2016a. Guest-editorial introduction: converging evolutionary pattern in life and culture. Evol. Biol. 43, 427-445.

Gontier, N., 2016b. Time: the biggest pattern in natural history research. Evol. Biol. 43, 604-637.

Gontier, N., 2017a. What Are the Units of Language Evolution. Topoi. http://dx.doi.org/10.1007/s11245-017-9474-8.

Gontier, N., 2017b. Hierarchies, Networks, and Causality: The Applied Evolutonary Epistemological Approach (forthcoming).

Gontier, N., Bradie, M., 2017. Acquiring knowledge on species-specific biorealities: the applied evolutionary epistemological approach. In: Joyce, R. (Ed.), Routledge Handbook of Philosophy of Biology. Routledge.

Gould, S.J., 1977. Ontogeny and Phylogeny. Harvard University Press, Cambridge, MA.

Gould, S.J., Eldredge, N., 1977. Punctuated equilibria: the tempo and mode of evolution reconsidered. Paleobiology 3 (2), 115-151.

Gould, S.J., Vrba, E.S., 1998. Exaptation: a missing term in the science of form. In: Hull, D., Ruse, M. (Eds.), The Philosophy of Biology. Oxford University Press, New York, pp. 52-71.

Gray, R.D., Drummond, A.J., Greenhill, S.J., 2009. Language phylogenies reveal expansion pulses and pauses in Pacific settlement. Science 323 (5913), 479483.

Gray, R., Jordan, F., 2000. Language trees support the express-train sequence of Austronesian expansion. Nature 405, 1052-1055.

Greenberg, J.H. (Ed.), 1963. Universals of Language. MIT Press, Cambridge.

Grene, M., 1987. Hierarchies in biology. Am. Sci. 75 (5), 504-510.

Griesemer, J., 2000. Development, culture and the units of inheritance. Philosophy Sci. 67, S348-S368.

Haeckel, E., 1874. Athropogenie oder Etnwickelungsgeschichte des Menschen. Engelmann, Leipzig.

Hallgrîmsson, B., Hall, B.K. (Eds.), 2011. Epigenetics: Linking Genotype and Phenotype in Development and Evolution. University of California Press, Berkeley, CA.

Hauser, M.D., Chomsky, N., Fitch, W.T., 2002. The faculty of language: What is it, who has it, and how did it evolve? Science 298, 1569-1580.

Haverkort, M., Stowe, L., 2002. The evolution of language: a neurolinguistic perspective. In: Brisard, F., Mortelmans, T. (Eds.), Language and Evolution. Universiteit Antwerpen, Departement Germaanse Talen, Afdeling Linguïstiek, pp. 27-38 (Antwerp Papers in Linguistics, 101.).

Hewes, G.W., 1977. Language origin theories. In: Rumbaugh, D.M. (Ed.), Language Learning by a Chimpanzee: The Lana Project. Academic Press, New York, pp. 3-53.

Hubbell, S.P., 2001. The Unified Neutral Theory of Biodiversity and Biogeography. Princeton Univ. Press, Princeton.

Hull, D.L., 1980. Individuality and selection. Annu. Rev. Ecol. Syst. 11, 311-332.

Hull, D.L., 1981. Units of evolution. In: Brandon, N.R., Burian, R.M. (Eds.), 1984. Genes, Organisms, Populations. MIT Press, Cambridge, MA, pp. $142-159$.

Jablonka, E., Lamb, M., 1989. The inheritance of acquired epigenetic variations. J. Theor. Biol. 139 (1), 69-83.

Jenkins, L., 2000. Biolinguistics: Exploring the Biology of Language. Cambridge University Press, Cambridge, MA.

Juergens, U., 2002. Neural pathways underlying vocal control. Neurosci. Biobehav. Rev. 26, 235-258.

Keeling, P.J., Palmer, J.D., 2008. Horizontal gene transfer in eukaryotic evolution. Nat Rev Genetics 9, 605-618. 
Kendon, A., 1975. Gesticulation, speech, and the gesture theory of language origins. Sign Lang. Stud. 9, 349-373.

Kimura, M., 1983. The Neutral Theory of Molecular Evolution. Cambridge University Press, Cambridge.

Labov, W., 2001. Principles of Linguistic Change, Vol. 2, Social Factors. Blackwell, Malden, MA.

Labov, W., 2010. Principles of Linguistic Change, Vol. 3, Cognitive and Cultural Factors. Wiley, Blackwell, Malden MA.

Leavens, D.A., Taglialatela, J.P., Hopkins, W.D., 2014. From grasping to grooming to gossip: innovative use of chimpanzee signals in novel environments supports both vocal and gestural theories of language origins. In: Pina, M., Gontier, N. (Eds.), The Evolution of Social Communication in Primates: A Multidisciplinary Approach. Springer, Dordrecht, pp. 179-194.

Leavens, D.A., Hopkins, W.D., Bard, K.A., 2005. Understanding the point of chimpanzee pointing: epigenesis and ecological validity. Curr. Dir. Psychol. Sci. 14 (4), 185-189.

Lenneberg, E., 1964. The capacity of language acquisition. In: Fodor, J., Katz, J. (Eds.), The Structure of Language. Prentice Hall, pp. 579-603.

Lenneberg, E., 1967. Biological Foundations of Language. John Wiley and Sons, New York.

Levinson, S.J., Holler, J., 2014. The origin of human multi-modal communication. Philos. Trans. R. Soc. B Ser. 369. http://dx.doi.org/10.1098/rstb.2013.0302. Lewontin, R., 1970. The levels of selection. Annu. Rev. Ecol. Syst. 1, 1-18.

Lewontin, R.C., 1983. Gene, organism and environment. In: Bendall, D.S. (Ed.), Evolution from Molecules to Men. Cambridge University Press, Cambridge, pp. 273-285.

Lieberman, P., 2007. The evolution of human speech: its anatomical and neural bases. Curr. Anthropol. 48 (1), 39-66.

Lumsden, C., Wilson, E., 1981. Genes, Mind and Culture: The Coevolutionary Process. Harvard University Press, Cambridge, MA.

Machamer, P., Darden, L., Carver, C.F., 2000. Thinking about mechanisms. Philosophy Sci. 67 (1), 1-25.

Malinowski, B., 1922. Ethnology and the study of society. Economica 2, 208-219.

Margulis, L., 1998. The Symbiotic Planet: A New Look at Evolution. Orion Books, London, Phoenix.

Martineau, H., 1865. The Positive Philosophy of Auguste Comte (1853), vol. 2. Chapman, London.

Maynard Smith, J., 1982. Evolution and the Theory of Games. Cambridge University Press, Cambridge (UK).

Mayr, E., 1961. Cause and effect in biology. Science 134 (3489), 1501-1506.

Mayr, E., 1982. The Growth of Biological Thought. Harvard University Press, Cambridge, MA.

McNeill, D., 1992. Hand and Mind: What Gestures Reveal about Thought. Chicago University Press, Chicago, IL.

Mendoza Straffon, L. (Ed.), 2016. Cultural Phylogenetics. Springer, Dordrecht.

Mesoudi, A., 2016. Cultural evolution: a review of theory, findings and controversies. Evol. Biol. 43, 481-497.

Moerman, J.G.M., 1932. In: van der Sijs, N. (Ed.), De Geheimtalen (2002). L.J. Veen, Amsterdam.

Morgan, L.H., 1877. Ancient society. Henry Holte Co, Arizona.

Morrison, D.A., 2016. Genealogies: pedigrees and phylogenies are reticulating networks, not just divergent trees. Evol. Biol. 43 (4), 456-473.

Mufwene, S., 2001. The Ecology of Language Evolution. CUP, Cambridge, MA.

Müller, M., 1866. Lectures on the Science of Language, Delivered at the Royal Institution of Great Britain in April, May and June 1861, fifth revised ed. Longmans, Green and Co, London.

Nelson-Sathi, S., List, J., Geisler, H., et al., 2010. Networks uncover hidden lexical borrowing in Indo-European language evolution. Proc. R. Soc. B Ser. http:// dx.doi.org/10.1098/rspb.2010.1917.

Odling-Smee, F.J., 1988. Niche-constructing phenotypes. In: Plotkin, H.C. (Ed.), The Role of Behavior in Evolution. MIT Press, Cambridge (MA), pp. 73-132. Okasha, S., 2005. Multilevel selection and the major transitions in evolution. Philosophy Biol. 72, 1013-1025.

Okasha, S., 2006. Evolution and the Levels of Selection. Clarendon Press, Oxford.

Pattee, H.H. (Ed.), 1973. Hierarchy Theory: The Challenge of Complex Systems. Braziller, New York.

Piaget, J., 1971. Genetic Epistemology. W.W. Norton, New York.

Pigliucci, M., 2009. An extended synthesis for evolutionary biology. The year in evolutionary biology 2009. Ann. N. Y. Acad. Sci. 1168, 218-228.

Pinker, S., 2003. Language as an adaptation to the cognitive niche. In: Christiansen, M., Kirby, S. (Eds.), Language Evolution. Oxford University Press, Oxford, pp. 16-37.

Pinker, S., Bloom, P., 1990. Natural language and natural selection. Behav. Bran Sci. 13 (4), 707-784.

Pinker, S., Jackendoff, R., 2005. The faculty of language: what's special about it? Cognition 95, 201-236.

Polyani, M., 1968. Life's irreducible structure. Science 160, 1308-1312.

Popper, K., 1957. The Poverty of Historicism. Routledge, London.

Puppel, S. (Ed.), 1995. The Biology of Language. John Benjamins publishing company, Amsterdam.

Reali, F., Griffiths, T.L., 2010. Words as alleles: connecting language evolution with Bayesian learners to models of genetic drift. Proc. Biol. Sci. 277 (1680), 429-436.

Rizzolatti, G., Fogassi, L., Gallese, V., 2006. Mirrors in the mind. Sci. Am. 295 (5), 54-61.

Rumbaugh, D.M. (Ed.), 1977. Language Learning by a Chimpanzee: The Lana Project. Academic Press, New York.

Sapir, E., 1917. Do we need a super-organic? Am. Anthropol. 19, 441-447.

Sapir, E., 1959 (1929). In: Mandelbaum, D.G. (Ed.), Culture, Language and Personality. University of California Press, Berkeley, CA.

Sapir, E., 1930. The Southern Paiute language (Part I): Southern Paiute, a Shoshonean language. Proc. Am. Acad. Arts Sci. 65, 1-296.

Schleicher, A., 1861/2. Compendium der vergleichenden Grammatik der indogermanischen Sprachen, vol. 2. H. Boehlau, Weimar.

Scott-Phillips, T.C., Kirby, S., 2010. Language evolution in the laboratory. Trends Cognitive Sci. 14 (9), 411-417.

Serrelli, E., Gontier, N. (Eds.), 2015. Macroevolution. Springer, Dordrecht.

Simon, H.A., 1962. The architecture of complexity: hierarchic systems. Proc. Am. Philos. Soc. 106, 467-482.

Skinner, B.F., 1957. Verbal Behavior. Appleton-Century Crofts Inc, New York.

Skinner, B.F., 1986. The evolution of verbal behaviour. J. Exp. Anal. Behav. 45, 115-122.

Smith, A., 1776. An Inquiry into the Nature and Causes of the Wealth of Nations, vol. 2. Strahan and Cadell, London.

Stebbins, G.L., 1959. The role of hybridization in evolution. Proc. Am. Philos. Soc. 103, 231-251.

Steels, L., 2006. Experiments on the emergence of human communication. Trends Cognitive Sci. 10 (8), 347-349.

Steels, L., Szathmáry, E., 2008. Replicator dynamics and language processing. In: Smith, A.D.M., Smith, K., Ferrer, I., Cancho, R. (Eds.), The Evolution of Language: Proceedings of the 7th International Conference. World Scientific, Signapore.

Tamariz, M., 2014. Experiments and simulations can inform evolutionary theories of the cultural evolution of language. In: Pina, M., Gontier, N. (Eds.), The Evolution of Social Communication in Primates: A Multidisciplinary Approach. Springer, Dordrecht, pp. 249-288.

Tattersall, I., 2014. Communication and human uniqueness. In: Pina, M., Gontier, N. (Eds.), The Evolution of Social Communication in Primates: A Multidisciplinary Approach. Springer, Dordrecht, pp. 219-227.

Tëmkin, I., Eldredge, N., 2015. Networks and hierarchies: approaching complexity in evolutionary theory. In: Serrelli, E., Gontier, N. (Eds.), Macroevolution. Springer, Dordrecht, pp. 183-226.

Tinbergen, N., 1963. On aims and methods of ethology. Z. Tierpsychol. 20, 410-433.

Tomasello, M., Call, J., 1997. Primate Cognition. Oxford University Press, New York.

von Humboldt, W., 1836. Über die Verschiedenheit des menschlichen Sprachbaus und ihren Einfluss auf die geistige Entwicklung des Menschengeschlechts. Könlinglichen Akademie der Wissenschaften, Berlin.

Vygotsky, L., 1986. Thought and Language, Translation Newly Revised and Edited by Alex Kozulin. MIT Press, Camridge, MA.

Wacewicz, S., 2012. The narrow faculty of language: what is it, who has it, and how is it defined? Theor. Hist. Sci. 9, 217-229.

Wacewicz, S., Zywiczynski, P., 2017. The multimodal origins of linguistic communication. Lang. Commun. http://dx.doi.org/10.1016/j.langcom.2016.10.001. 
Wagner, G.P., Altenberg, L., 1996. Complex adaptations and the evolution of evolvability. Evolution 50, 967-976.

West-Eberhard, M.J., 2005. Phenotypic accommodation: adaptive innovation due to developmental plasticity. J. Exp. Zool. B Mol. Dev. Evol. 304 (6), $610-618$.

Williams, G., 1966. Adaptation and Natural Selection. Princeton University Press, Princeton, NJ.

Wilson, E.O., 1975. Sociobiology: The New Synthesis. Belknap Press of Harvard University Press, Cambridge (MA).

Wimsatt, W.C., Schank, J.C., 2004. Generative entrenchment, modularity and evolvability: when genic selection meets the whole organism. In: Schlosser, G., Wagner, G. (Eds.), Modularity in Development and Evolution. University of Chicago Press, Chicago, IL, pp. 359-394.

Woese, C.R., 1998. The universal ancestor. PNAS 95 (12), 6854-6859.

Wray, A., 1998. Protolanguage as a holistic system for social interaction. Lang. Commun. 18, 47-67.

Wray, A., Grace, G.W., 2007. The consequences of talking to strangers: evolutionary corollaries of socio-cultural influences on linguistic form. Lingua 117 (3), $543-578$.

Zlatev, J., 2014. Bodily mimesis and the transition to speech. In: Pina, M., Gontier, N. (Eds.), The Evolution of Social Communication in Primates: A Multidisciplinary Approach. Springer, Dordrecht, pp. 165-178.

Zywiczynski, P., Gontier, N., Wacewicz, S., 2017. The evolution of (proto-) language: focus on mechanisms. Lang. Sci. 63, 1-11. http://dx.doi.org/10.1016/j. langsci.2017.06.004. 